UNIVERSIDADE ESTADUAL PAULISTA “JULIO MESQUITA FILHO" FACULDADE DE MEDICINA DE BOTUCATU

Programa de Pós Graduação-Mestrado Profissional

Pesquisa e Desenvolvimento: Biotecnologia Médica

AVALIAÇÃO DA INTERVENÇÃO PSICOTERAPÊUTICA DE MODELO ANALIITICO EM CRIANÇAS E ADOLESCENTES COM DOENÇAS ONCO-HEMATOLÓGICAS

Silvana Oliveira Cantu 
UNIVERSIDADE ESTADUAL PAULISTA “JULIO MESQUITA FILHO” FACULDADE DE MEDICINA DE BOTUCATU

Programa de Pós Graduação-Mestrado Profissional

Pesquisa e Desenvolvimento: Biotecnologia Médica

\title{
AVALIAÇÃO DA INTERVENÇÃO PSICOTERAPÊUTICA DE MODELO ANALÍTICO EM CRIANÇAS E ADOLESCENTES COM DOENÇAS ONCO-HEMATOLÓGICAS
}

Silvana Oliveira Cantu

Orientadora: Profa. Dra. Elenice Deffune

\begin{abstract}
Dissertação apresentada ao Programa de Pós-Graduação em Pesquisa e Desenvolvimento: Biotecnologia Médica, curso de Mestrado Profissionalizante do Hemocentro de Botucatu, Faculdade de Medicina de Botucatu. UNESP, como requisito para a obtenção do título de Mestre em Biotecnologia Médica. Botucatu-SP 2010.
\end{abstract}




\section{Ficha catalográfica}

Cantu, Silvana Oliveira

Avaliação da intervenção psicoterapêutica de modelo analítico em crianças e adolescentes com doenças onco-hematológicas / Silvana Oliveira Cantu. - 2010.

Dissertação (mestrado) - Faculdade de Medicina de Botucatu, Universidade Estadual Paulista, 2010

1. Neoplasias hematológicas. 2. Estresse psicológico. 3. Criança. 
À Deus, pela presença em minha vida. 


\section{Dedicatória}

Dedico esse estudo aos meus pais, que me ensinaram coisas valiosas; minha mãe Rute, pelo amor, ajuda e incentivo, e ao meu pai Waldemar, que passou pela experiência de ter um câncer, partindo deixando muitas saudades. Amo vocês. 
A minha filha Nathália, meu amor eterno.

Agradeço por tudo que tem acrescentado à minha vida, e pela maravilhosa oportunidade de ser mãe, de querer ser a cada dia uma pessoa melhor. 


\section{Agradecimentos}

À minha orientadora Prof ${ }^{\mathbf{a}}$ Dr $^{\mathbf{a}}$ Elenice Deffune, por todo o acolhimento, ensinamento e saber. Meu muito obrigado.

Ao Prof ${ }^{0}$ Dr$^{0}$ Sebastião Marcos R. de Carvalho, meu eterno obrigado. Sem a sua dedicação e trabalho esse estudo não seria possível.

À Dra Doralice Marvulle Tan, minha amiga e colega de trabalho, obrigado pelo apoio e confiança recebido para a execução do estudo.

À Prfa Dra Renata Baldissera, agradeço pelo incentivo e apoio.

Aos colegas de trabalho do Ambulatório de Onco-hemato do Hemocentro da Faculdade de Medicina de Marilia, por terem acreditado no meu trabalho e favorecido a sua realização.

Aos meus irmãos e minha família, por fazerem parte da minha vida.

À minha amiga Vera Contieiro, pela amizade sólida e verdadeira em todos os momentos da minha vida.

Às minhas amigas Rita Arantes e Carina Gomide, obrigado pelo incentivo e ajuda.

À Roseli e Neto, meus amigos, agradeço pela escuta e carinho que sempre me acolheram.

Ao meu amigo Marcelo Souto pela confiança e incentivo na minha vida.

Ao amigo e colega de trabalho Fabricio Mazoti que me ajudou a enfrentar este desafio.

À Angélica Cantu, pela dedicação e empenho na construção desse trabalho. Meu eterno obrigado.

À Lara Ravazzi, minha filha do coração obrigado por fazer parte da minha vida e pela ajuda na construção deste trabalho.

À minha amiga e colega de trabalho Danielle Massi Pio, obrigado pela ajuda e carinho que sempre me acolheu.

Às crianças, aos adolescentes, participantes deste estudo, obrigado pelo carinho, pela demonstração de luta e vontade de viver.

Eles começaram a lutar cedo pela vida! 


\section{RESUMO}

O processo de adoecer provoca uma crise vital para a pessoa. Na criança traz repercussões mais sérias, pois os conteúdos do inconsciente estão ainda pouco discriminados pelo ego e nesta situação pela percepção da possibilidade de desintegração ou morte, alguns destes conteúdos tornou-se mais intrusos e ameaçadores. Enfermidades graves durante a infância ou na adolescência tais como, as neoplasias, doenças cardíacas, insuficiência renal, diabetes, doenças com má formação genéticas, doenças hematológicas, dentre outras, conduzem o paciente e seus familiares a situações de crise, manifesta por estresse emocional e comportamental, perturbações da auto-imagem e auto-estima, comprometimento da qualidade de vida, dentre outros sintomas psicopatológicos. O objetivo deste trabalho foi o de avaliar a intervenção psicoterápica em modelo analítico em crianças e adolescentes com doenças onco-hematológicas. Foram utilizados dois instrumentos de avaliação: inventários de estresse e depressão infantil (ISI e CDI) aplicados em 4 diferentes momentos após a primeira avaliação: TO, T30, T60 , T90 e T120. Foram acompanhados 7 pacientes do ambulatório de psicologia OEI do Hemocentro de Marília. Trata-se de um ensaio clínico não-randomizado intra-grupos de séries temporais, no qual a intervenção foi realizada com um único grupo e os desfechos foram comparados em cada participante durante diferentes períodos desta intervenção. A análise dos escores CDI ao final do período das intervenções observou-se uma melhora no estado geral dos sintomas de depressão dos participantes (escores finais aos 120 dias inferiores a 17) comprovando a eficácia da intervenção psicoterápica de base analítica na melhora dos sintomas em crianças e adolescentes portadores de neoplasias onco-hematológicos. Os dados dos inventários de estresse infantil são semelhantes aos de depressão apontando para a eficácia da abordagem psicoterápica. As variáveis da fase reações físicas (ESI) estão associadas aos índices de presença e gravidade do transtorno depressivo (CDI) nos momentos inicial e final deste estudo.

Palavras-chave: neoplasias hematológicas; estresse psicológico; criança 


\begin{abstract}
The process of getting sick causes a vital crisis to the person. It brings more severe repercussions to the children since the unconscious contents are hardly discriminates by the ego and, in this special situation, by the perception of the possibility of disintegration or even death. So some of these contents become more threatening. Serious diseases during childhood or adolescence such as neoplasi, cardio illness, kidney insufficiency, diabetes, genetics and blood problems, among others, lead the patient and his family members to crises with emotional and behavior stress, self-esteem disturbance, even involving the daily life and other psychopathic symptoms.
\end{abstract}

The objective on this paper was to evaluate a psychotherapeutic intervention in an analytical pattern for children and teenagers with onco-hemathology diseases.

Two models for evaluation were used:

Stress inventory and depression on in children (ISI and CDI) applied in four different times after the first evaluation: TO, T30, T60, T90 and T12.

Seven patients of the psychology ambulatory OEI in the Hemocentro in Marilia were watched.

It is a clinic essay not at random among groups on specific times in which the intervention was accomplished with a unique group and the results were compared on each participant in different times. In the analyses of the scores CDI in the end of interventions, some improvements in the overall depression symptoms were clearly noticed (final scores in 120 days bellow 17) proving the effectiveness of the psychotherapeutic intervention based on the analysis of the symptoms in kids and teen suffering from neoplasi and oncohematology diseases.

The inventory data inn children stress are similar to the depression pointing to the effectives of the psychotherapeutic approach.

The variations of the physical reactions (ESI) are related to the rates of presence and severety of depressing disturbance in this inicial and final paper.

Key -words: neoplasi hematologyc; psychological stress; child. 


\section{SUMÁRIO}

1. INTRODUÇ̃̃O ............................................................................... 1

2. OBJETIVOS ……............................................................................. 27

2.1 Objetivo geral ................................................................................... 27

2.2 Objetivos específicos .......................................................................... 27

3. CASUÍSTICA E MÉTODOS ................................................... 28

3.1 Casuística ....................................................................................... 28

3.2 Desenho do estudo ........................................................................ 29

3.3 Desenvolvimento, local e período de estudo .................................. 29

3.4 Instrumentos ........................................................................................ 29

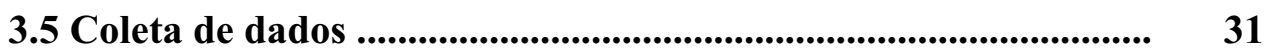

3.6 Intervenção Psicoterepêutica - IPS ............................................... 32

3.7 Procedimentos .............................................................................. 32

3.8 Análise de dados .......................................................................... 33

4. RESULTADOS E DISCUSSÃO ............................................... 36

4.1 Inventário de depressão infantil (CDI) ......................................... 36

4.2 Escala de Stress Infantil (ESI) ...................................................... 38

4.3 Correlação entre idade, sexo, escores CDI e ESI ........................ 49

5. CONCLUSÃO …...................................................................... 50

REFERÊNCIAS ...................................................................... 51

APÊNDICE A - Termo de Consentimento Livre e Esclarecido ...... 54

ANEXO A - CDI .................................................................................... 56

ANEXO B - ESI ............................................................................... 58

ANEXO C - AVALIAÇÃO DOS RESULTADOS ESI ...................... 


\section{INTRODUÇÃ̃O}

Segundo a Sociedade Francesa de Oncologia Pediátrica a cada ano, em média 1800 crianças são acometidos de câncer na França, ou seja, uma criança a cada 600. Tendo em vista que as taxas de curas e remissões completas progrediram consideravelmente nos últimos 20 anos, estes pacientes oncológicos ocupam ainda a segunda causa de mortalidade na infância de países de primeiro mundo perdendo apenas para traumas.

A freqüência destes tumores malignos varia conforme a idade. Cada tumor tem uma idade preferencial de surgimento : por exemplo, na primeira infância o predomínio e para nefroblastomas, neuroblastomas, e radbomiosarcomas, na segunda infância, os tumores ósseos, linfomas e leucemias.

Dentre as neoplasias, aquelas que ocupam papel preponderante estão as leucemias, correspondendo em média a $30 \%$ de todas as neoplasias malignas.

No Brasil, a partir dos dados obtidos do Registro Brasileiro de Câncer Pediátrico do Instituto Nacional do Câncer-INCA, observou-se que os tumores pediátricos variaram de 1,0\% (Palmas, 2000-2001) a 4,6\% (Campo Grande, 2000), e que os mais freqüentes também foram leucemias, linfomas e tumores do sistema nervoso central. A leucemia é o câncer de maior ocorrência em crianças. Na maioria dos países, crianças abaixo de 5 anos são as mais freqüentemente acometidas por este tipo de neoplasia. No Brasil, a variação percentual deste tumor foi de 45\% (Manaus, 1999) a 15\% (Belo Horizonte, 2000). O gráfico 1 registra estas diferenças. 


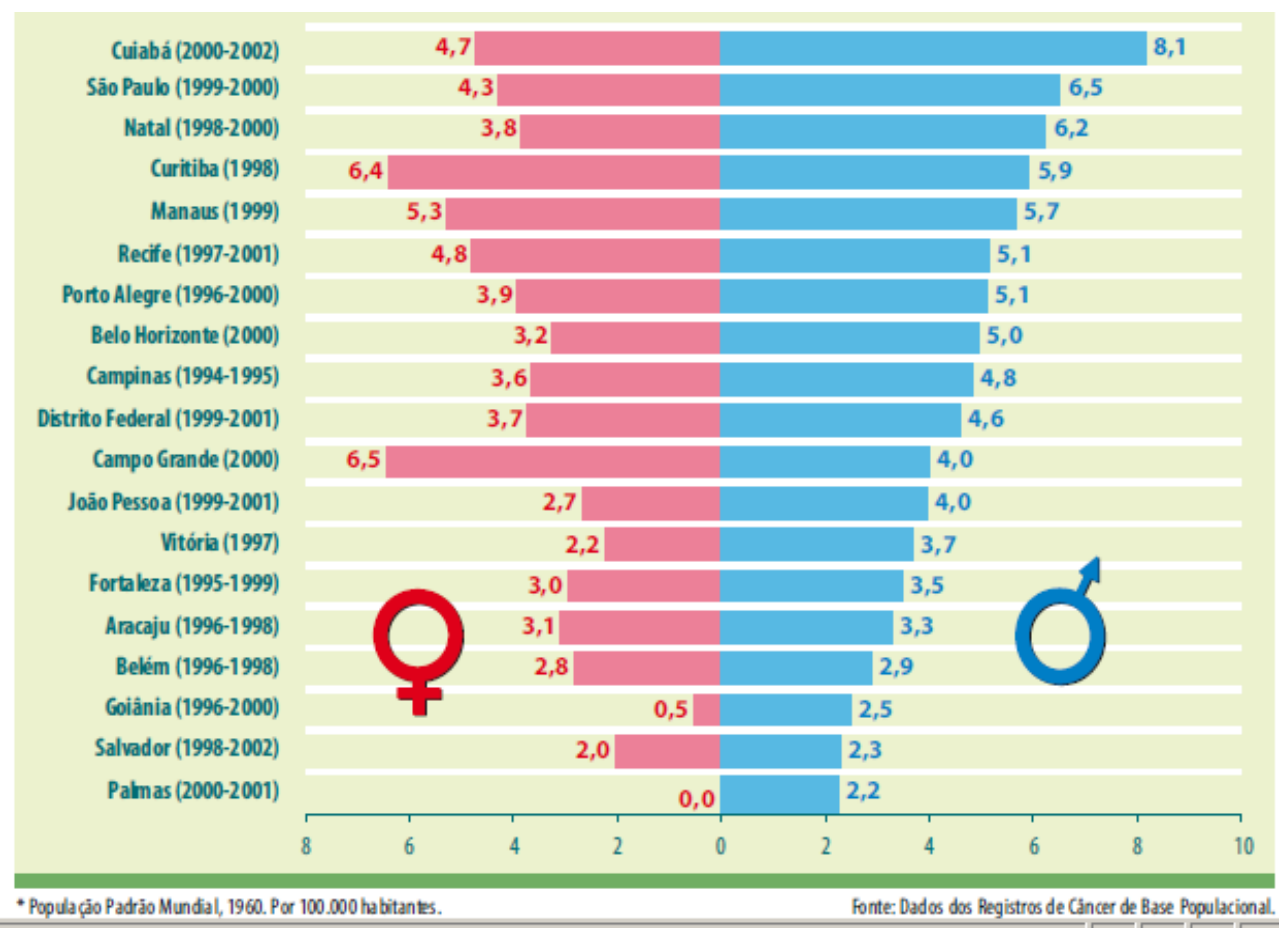

Gráfico 1- Distribuição das taxas de incidência de leucemias infantis, ajustado por idade, em meninos e meninas, em capitais brasileiras

A eficácia crescente da quimioterapia, a cada vez mais sob controle clínico, os conhecimentos mais precisos das conseqüências a longo termo da radioterapia, a precocidade de diagnóstico, tudo isto tem levado ao estabelecimento de protocolos de tratamento com aumento da longevidade dos pacientes, índices crescentes de remissão completa e necessidade de intervenção multidisciplinar do paciente. Dentro deste panorama se situa a atuação da psicologia da criança e do adolescente como terapêutica de apoio ao tratamento do câncer. Para entendermos melhor a interação da Psicologia com a Oncologia pediatria, algumas considerações se fazem necessário, entre elas, o resgate da atuação da psicoterapia.

A Psicologia vem sendo reconhecida cada vez mais na prática médica, mas nem sempre tem o reconhecimento que deveria nas instituições de saúde.

A noção de que o corpo e a mente são parte de um organismo e que a saúde é fruto deste equilíbrio entre as partes do indivíduo e deste com o meio ambiente, já estava presente nos estudos da Medicina Ocidental, Hipócrates e Galeno. 
Ainda no segundo século depois de Cristo, Galeno, considerado um dos pais da Medicina, observou que mulheres "melancólicas" pareciam ser mais susceptíveis a desenvolver um câncer do que aquelas que ele chamava de "sanguíneas".

Se na antiguidade médicos como Hipócrates, Galeno e outros acreditavam que o que passava na mente influenciava o que passava no corpo e vice-versa, o pensamento cartesiano trouxe mudanças importantes quando propôs que o corpo e mente, respectivamente são de natureza distinta, devendo ser estudados através de metodologia própria. Todo desenvolvimento da medicina ficou assim influenciado. Com o passar dos anos e com os avanços científicos e tecnológicos, ocorreu de uma forma intensa a busca de uma etiologia específica, para cada doença, proporcionando uma visão mais holística (de todo) do homem.

Foi apenas na transição do século passado para este que, na origem da Psicanálise, com os estudos de Charcot, e mais precisamente de Freud sobre a histeria, se retornou a visão sobre a estreita relação entre fenômenos físicos e psíquicos, visão proibida nos séculos anteriores. Ele demonstrou que acontecimentos psíquicos podiam ter conseqüências orgânicas e abriu caminho para que inúmeras pesquisas buscassem as interpretações entre os aspectos biológicos, psicológicos e sociais do ser humano. (Carvalho, 1998.)

Com as descobertas da psicanálise, demonstrou-se que as emoções e afetos, ligados a experiências passadas e mal elaboradas, poderiam dar origem a formação de sintomas físicos.

O lócus interno de controle de saúde torna o individuo responsável pela suas escolhas, participando ativamente de sua recuperação. Cada um participa na saúde ou na doença, a todo o momento.

O trabalho de Freud e seus seguidores proporcionam o desenvolvimento de um campo de estudos, pesquisa e atuação, denominado Medicina Psicossomática, passando este termo a significar, na literatura atual, a interface entre mente e corpo.

As noções da psicossomática custaram muito para serem assimiladas e só foram ganhar um novo impulso bastante recente com os avanços dos estudos sobre o sistema imunológico. Paradoxalmente, portanto a tentativa de compreensão cada vez mais precisa da origem e desenvolvimento das doenças, que levaram as tantas especializações, entre elas a imunologia, acabou por trazer de volta o enfoque multifatorial. Isto porque se provou que 
o sistema imunológico, dentro o organismo, inter-relaciona-se com outros sistemas e pode ter seu funcionamento influenciado por fatores emocionais.

Entre as células do sistema nervoso e o sistema imune, existem células dotadas de memória e tem função defensiva, contribuindo para a homeostasia e o autoreconhecimento, porém, quando funcionam adaptativamente mal, costumam provocar enfermidades.

A literatura aponta a importância do componente emocional como, coadjuvante do processo terapêutico em várias doenças. Ao que tudo indica as emoções desempenham papel importante no sistema imunológico e é crucial não só para o processo de cura como para o seguimento e desenvolvimento da própria doença.

Adoecer representa uma situação crítica na vida de uma pessoa onde o indivíduo terá de encontrar recursos para tal enfrentamento. A doença é um ataque ao organismo como um todo, estando o seu estado emocional também atingido, sendo afetado em sua integridade.

Estudos multicêntricos identificam claramente a relação entre alterações psicológicas e aparecimento/crescimento de neoplasia. Inúmeros pesquisadores vêm estudando possíveis efeitos dos estados emocionais na modificação hormonal e desta na alteração do sistema imunológico. A relação entre estresse e depressão com o desenvolvimento de formações tumorais foram amplamente analisadas por Lê Shan (1992), Simonton e Creighton (1987) pioneiros nos estudos envolvidos no processo do câncer. Seus trabalhos mostram a possibilidade de auxilio no encontro de uma melhor forma de enfrentar o processo de adoecer, o enfrentamento com o câncer e a obtenção de uma melhor qualidade de vida. Seigel (1989) refere que o desenvolvimento de uma enfermidade está diretamente relacionado com o modo de interpretar os acontecimentos e a capacidade de lidar com as tensões e as emoções.

Cannon, é outro autor que introduziu o conceito de "homeostase" em medicina, como o estado de equilíbrio que o organismo sempre busca manter, procurando afastar qualquer estímulo que possa ser nocivo a ele, vindo de fontes internas ou externas, desde que ultrapasse um certo limiar. Um perigo real ou imaginário é capaz de acionar o organismo, colocando-o em estado de alerta e desencadeando as relações de luta ou de fuga diante da situação. Para esse autor, qualquer situação que coloque em risco a "homeostase" 
do organismo, incluindo medo, raiva, dor e outros estados de desconforto, coloca em ação o sistema de emergência.

Inúmeros estudos desenvolveram-se com base nesse modelo, buscando correlacionar os estados de tensão emocional com as alterações fisiológicas.

Segundo a teoria da vigilância imunológica e a susceptibilidade ao câncer (SIMONTON et al, 1987) todos nós produzimos células anormais no corpo, de tempos em tempos. Em geral o sistema imunológico do organismo vigia de perto o aparecimento de células anormais e as destrói. Para que o câncer possa ocorrer é necessário que o sistema imunológico esteja inibido de alguma maneira. Níveis elevados de estresse emocional aumentam a susceptibilidade a doenças, leva a supressão do sistema imunológico, o que por sua vez, aumenta o desequilíbrio emocional e aumenta a produção de células anormais, quando o organismo se encontra menos capacitado para destruí-las.

As imagens mentais do sistema imunológico atuam no combate às células cancerosas.

A evolução biotecnológica e os programas de prevenção e diagnóstico precoce do câncer são determinantes para as atuais estatísticas mundias. $\mathrm{Na}$ dependência do estadiamento da neoplasia, grande parte delas apresentam cura. A sobrevida dos pacientes oncológicos tem aumentado consideravelmente, o que implica na necessidade de se pensar na sua qualidade de vida.

Seu desenvolvimento poderá resultar em mudanças nas práticas assistências e na consolidação de novos paradigmas do processo saúde-doença, o que pode ser de grande valia para a superação de modelo de atendimento eminentemente biomédicos, que negligenciam aspectos sócio-econômicos, psicológicos e culturais importante nas ações de promoção, prevenção, tratamento e reabilitação da saúde. Assim, sendo qualidade de vida um constrito interdisciplinar, a contribuição de diferentes áreas do conhecimento pode ser de fato valiosa e indispensável.

A mudança do perfil de morbitalidade, tendência universal também nos paises em desenvolvimento, indica o aumento da prevalência das doenças crônico-degenerativas. Os avanços nos tratamentos e as possibilidades efetivas de controle dessas enfermidades têm acarretado o aumento da sobrevida e/ou a vida longa das pessoas acometidas por esses agravos. A propósito, Fleck et al (p 20) assinalaram que "a Oncologia foi a especialidade 
que, por excelência, se viu confrontada com a necessidade de avaliar as condições de vida dos pacientes que tinham sua sobrevida aumentada devido aos tratamentos realizados, já que muitas vezes, na busca de acrescentar anos à vida, era deixada de lado as necessidades de acrescentar "vida aos anos".

Câncer ou enfermidades oncológicas, são denominações utilizadas para descrever um grupo de doenças, que se caracterizam pela anormalidade das células e sua divisão excessiva. Pode ser vista, como uma doença resultante de um processo de múltiplos estágios de crescimento e desenvolvimento que se desenvolveu de forma incorreta, onde células malignas concentram suas energias na reprodução, em vez de participarem das metas que um tecido tem, para manter a vida do organismo.

De acordo com Pereira (2001), o câncer caracteriza-se por uma proliferação anormal das células, destruindo os tecidos do organismo, pois formam “[...] uma grande variedade de neoplasias ou tumores malignos, que causam efeitos destrutivos no organismo, devido ao caráter invasivo e metastático".

Existe uma grande variedade de tipos de câncer. O carcinoma, que surge nos tecidos epiteliais; o sarcoma, que ocorre nas estruturas de tecidos conectivos, como ossos e músculos; a leucemia que se origina na medula óssea e afeta o sangue; o melanoma que é um câncer de pele; e muitos outros (CARVALHO, 2000).

Por ter aspectos clínicos e localizações diversas, pode ser detectado em vários estágios de evolução. Em geral, o câncer não se origina através de uma única causa, mas através de múltiplos fatores, por isso se diz que o câncer é uma enfermidade multifatorial.

É uma doença de proporções graves, pois ameaça a vida, podendo afetar qualquer parte do organismo, atacando pessoas de todas as idades, ocorrendo quase com a mesma proporção para ambos os sexos; podendo ser definida como uma doença degenerativa , resultante do acúmulo de lesões no material genético das células, que induz o processo de crescimento, reprodução e dispersão anormal das mesmas, no qual o controle sobre a proliferação e morte celular está alterado (YAMAGUCHI, 1999).

De maneira ampla, as suas causas podem ser internas ou externas ao organismo, estando de certa forma inter-relacionadas. As causas internas, em sua maioria são prédeterminadas geneticamente e as externas estão relacionadas ao meio ambiente, aos hábitos e costumes próprios. 
Em geral, é uma doença que não produz sintomas, quando isto ocorre, significa que a enfermidade está muito avançada. Conseqüentemente, a detecção rápida é de vital importância para o êxito no tratamento dessa patologia.

O diagnóstico precoce é geralmente difícil de ser alcançado na maioria dos tumores, pois a progressão da doença desde o início é silenciosa, limitando-se as possibilidades de tratamento.

Os avanços obtidos na compreensão da doença, em termos de comportamento clínico ou quanto à patogênese molecular, traduziram-se em progressos importantes. Atualmente, são muitos os recursos terapêuticos para o tratamento do câncer, porém difíceis de enfrentar, pois cada um deles, com suas peculiaridades acarretam efeitos colaterais e reações psicológicas (DEITOS GASPARY, 1997; ROQUE, FORONES, 2006).

Em função de uma maior precocidade na detecção do câncer, tem ocorrido melhor eficácia dos tratamentos, aumentando o número de sobreviventes e propiciando uma melhor qualidade de vida. Nesse contexto, as pessoas com câncer querem sentir que a sua sobrevida significa mais "que um escape à morte".

O tratamento do câncer está determinado por sua localização e pelo avanço em que foi diagnosticada a enfermidade. As principais formas de tratamento são: cirurgia, radioterapia e a quimioterapia.

A cirurgia é a técnica mais antiga para o tratamento do câncer e consiste na retirada do tumor do tecido afetado, sendo a mais indicada nos casos de tumores sólidos. Dependendo da localização e do tamanho do tumor, ela pode ser a primeira parte do tratamento ou pode ser realizada após sua redução, por quimioterapia ou radioterapia (HOSPITAL DO CÂNCER, 2003).

A quimioterapia é um tratamento que se utiliza de medicamentos para destruir as células tumorais, cuja finalidade é bloquear a capacidade de reprodução das mesmas, esses medicamentos podem ser administrados oralmente ou injetados diretamente no sangue. Sua freqüência e duração dependem de cada caso e protocolo.

A quimioterapia pode ser usada para curar, quando o câncer é considerado curável; para controlar, impedindo o seu crescimento, eliminando as células que podem ter se espalhado por outras partes do corpo; e para aliviar os sintomas, como dor, com o objetivo de ajudar os pacientes a viver mais confortavelmente. 
A rotina e as exigências desse tratamento colocam o paciente em situações de conflito, exigindo que este venha a habituar-se a uma vida estritamente ordenada, cheia de restrições, submetendo-se a procedimentos muitas vezes dolorosos, além da mudança de hábitos.

Portanto, ao prescrevê-la, é preciso ponderar seus benefícios e malefícios, levandose sempre em consideração as opiniões e vontades dos pacientes. Essa atitude torna -se ainda mais importante quando se trata de uma segunda quimioterapia, principalmente em casos de recidivas, já que a experiência pode ser traumatizante, influenciando muito na decisão de aceitar ou não, esse segundo tratamento. (RODRIGUES e CAMARGO, 2003).

A radioterapia é um método que é capaz de destruir células tumorais, empregando feixes de radiação ionizante. Uma dose pré-calculada de radiação é aplicada, em um determinado tempo, a um volume de tecido que engloba o tumor, buscando erradicar todas as células tumorais, com o menor dano possível às células normais circunvizinhas, à custa das quais se fará a regeneração da área irradiada. A radioterapia pode ser curativa, remissiva, profilática, paliativa.

Os efeitos colaterais mais comuns são: irritações ou leves queimaduras na pele e diminuição das células do sangue (CAMARGO; MARX, 2000).

Trabalhar na onco-hematológica historicamente envolvia a aceitação de um prognóstico difícil, onde o papel da equipe era principalmente minimizar o desconforto do paciente e preparar a família para a morte inevitável. Com o desenvolvimento do tratamento do câncer pediátrico nas últimas quatro décadas o enorme fluxo de conhecimentos na área e a inserção de equipes multidisciplinar na assistência a criança com câncer provocaram um aumento significativo nas taxas de sobrevida e melhoria da qualidade de vida, o prognóstico melhorou significativamente,sendo considerado uma doença potencialmente curável.Mesmo assim, a doença ainda é a segunda causa de mortalidade infantil no Brasil e também em países desenvolvidos.

O Câncer infantil difere do câncer adulto em relação ao local, histologia, desenvolvimento, estados clínico e diversos outros fatores.

Em várias regiões do Brasil, as taxas de cura do câncer infantil fica comprometida, devido a uma série de fatores como a falta de hospitais especializadas em oncologia 
pediátrica falta de profissionais especializados e ao diagnóstico tardio da doença na rede básica de saúde.

O câncer pediátrico representa entre 0.5 e 3\% de todas as neoplasias na maioria das populações. Em geral, a incidência total de tumores malignos na infância e maior no sexo masculino.

Dos cânceres infantis, a Leucemia é o tipo mais freqüente, dentre essas, a Leucemia Linfóide Aguda (LLA) é a de maior ocorrência em crianças. Entre os linfomas, o de maior incidência na infância é o Linfoma Não-Hodking.Os tumores de sistema nervoso que predominam no sexo masculino,ocorrem principalmente em crianças, menores de 15 anos, com um pico na idade de 10 anos, e representam cerca de $20 \%$ dos tumores infantis.Os tumores ósseos tem sua maior ocorrência nos adolescentes.O retinoblastoma é responsável por cerca de $2 \%$ dos tumores infantis.

As estatísticas sobre a incidência do câncer infantil indicam que as Leucemias encontram-se entre os tipos mais comuns e são classificadas como agudas e crônicas.

No Brasil anualmente de 12 a 13 mil crianças menores de 14 anos são acometidas por câncer e destas $70 \%$ podem ser consideradas curadas dependendo da precocidade do diagnóstico.

O aumento da sobrevida de crianças e adolescentes com Leucemia que ora vem ocorrendo no Brasil, a semelhança de outros países, é decorrente ao trabalho multidisciplinar, ou seja, na utilização de métodos de diagnósticos mais acurados, da evolução de medicamentos e agentes que proporcionam suporte contra infecção da evolução de novas modalidades hemoterápicas, o transplante de medula óssea e a intervenção psicossocial.

Esta configuração atual do câncer infantil gera necessidades especificas na área da assistência, impondo a necessidade de transformações nas práticas de saúde organizadas para atender a criança. Essas transformações, apontam a importância da inclusão da equipe multidisciplinar, capaz de compreender a criança com câncer em sua especificidade, com determinações familiares, ambientais, emocionais e culturais.

As questões relacionadas ao câncer infantil passam, portanto a receber enfoques novos. Os estudos buscam dar conta da complexidade do assunto a ele relacionados e a dimensão psicossocial do processo de adoecer. Visam sistematizar os novos saberes, 
contribuindo para a organização assistencial dos serviços de saúde, No sentido de atender as necessidades globais dos pacientes e das pessoas que os cercam, incluindo os membros da equipe, a fim de viabilizar diagnósticos precoces, tratamentos efetivos e abordagens adequadas á complexidade das situações que se configuram em torno da doença e da criança que adoece.

O diagnóstico e o manejo do câncer infantil se tornam um desafio para a equipe de cuidado multidisciplinar. Particularmente, com crianças menores este desafio é ainda maior, devido a excepcional vulnerabilidade delas e complicações agudas, decorrentes de terapia multimodais agressivas e ao potencial de seqüelas dos tratamentos antineoplásicos no seu crescimento e desenvolvimento em longo prazo.

\section{Aspectos Psicológicos do Paciente Pediátrico com Doença Grave}

O processo de adoecer provoca uma crise vital para a pessoa. Na criança traz repercussões mais sérias, pois os conteúdos do inconsciente estão ainda pouco discriminados pelo ego e nesta situação pela percepção da possibilidade de desintegração ou morte, alguns destes conteúdos tornou-se mais intrusos e ameaçadores.

Enfermidades graves durante a infância ou na adolescência tais como, as neoplasias, doenças cardíacas, insuficiência renal, diabetes, doenças com má formação genéticas, doenças hematológicas, dentre outras, conduzem o paciente e seus familiares a situações de crise, manifesta por estresse emocional e comportamental, perturbações da auto-imagem e auto-estima, comprometimento da qualidade de vida, dentre outros sintomas psicopatológicos. Assim cada vez mais tem sido proposto que um sistema integrado de atenção e assistência ao paciente deve incluir a avaliação psicológica e atendimento psicoterápico aos pacientes e seus familiares.

Diante da doença a criança demonstra sua consciência ameaçada.

O medo está presente no desenvolvimento normal da criança desde o nascimento, o contato com o mundo externo está relacionado ao medo da morte. Esses sentimentos de medo surgem independentes das diversas patologias e estão associados ao medo da morte.

$\mathrm{O}$ fato de surgirem nas crianças nesse momento mesmo quando existe em prognóstico favorável, ou quando ela esta bem adapta ao tratamento, o medo de morrer está 
presente. A agressividade é comum na criança que tem medo. Na psique infantil, as figuras ameaçadas são projetadas de forma intensificada. Quando por exemplo, há uma doença com sério risco de morte, os monstros, dragões, ladrões, etc, tornam-se ainda mais terríveis, o medo aumenta e a agressividade é reforçada, para se defender deste mundo hostil (psíquico e concreto)

Segundo KOVACS (1992), não se pode esquecer que as crianças têm um contato direto e inteiro com o seu corpo, percebem a deterioração que a doença provoca. Por outro lado, muitas vezes em suas perguntas pedem um esclarecimento e confirmação de algo que já sabem.

O velamento da verdade provoca um sentimento de estar sendo enganado ou considerado ingênuo, o que causa um sentimento de profunda solidão (KOVACS, 1992).

A doença crônica infantil pode ser vista como um estressor complexo, em que se somam as hospitalizações, vivências de dor, as explorações medidas, os remédios, ás restrições nas atividades diárias, os temores, as fantasias. O impacto sobre a criança dependera da duração, sintomatologia, gravidade, visibilidade da doença, tipos de intervenção médica que requer características da criança e das relações familiares. A hospitalização pode ter conseqüências imediatas para algumas crianças, como o aparecimento dos conflitos e fantasias (KOVACS, 1962).

O conceito de doença, para as crianças e adolescentes, passa por um processo evolutivo que está mais diretamente relacionado a seu nível cognitivo e a idade em que está vivenciando esse processo (KOVACS, 1962).

Hospitalizações, procedimentos médicos e cirurgias são situações estressantes para as crianças e adolescentes em todas as idades a repetições de hospitalizações e experiências médicas estressantes podem prejudicar o desenvolvimento psíquico, cognitivo, físico e social da criança. É essencial que os profissionais da saúde saibam reconhecer as situações potencialmente estressantes para introduzir intervenções apropriadas e facilitar a utilização de crescimento de cada criança.

A inserção do psicólogo na pediatria, tornou possível um conhecimento mais vasto da interação desses aspectos com a criança e processo de adoecer. O psicólogo inserido neste contexto hospitalar trouxe um elemento muito importante: um espaço para a escuta para os pacientes, sua família e a equipe. 
É importante considerar que aborrecimentos graves, quando ocorridos no início da infância, acarretam problemas relativos à intromissão prematura da realidade, em uma fase onde a criança deve poder experimentar a sua própria onipotência no contato com o ambiente.

Quando se leva em conta o atendimento de pacientes adolescentes, e necessário considerar que em alguns casos pode haver uma crise prévia, própria à puberdade, ao lado da crise despertada pelo adolescente (Freud, 1905; Ferrari, 1994). Esta situação compromete, por exemplo, a aliança terapêutica com a equipe ou a relação do paciente com seus familiares, dado que lhe é dificultoso assumir uma posições de dependência em relação aos demais cuidadores neste momento em que a independência é tão desejada.

Em relação às doenças onco-hematológicas, especificamente as leucemias na infância e na adolescência, apesar de grandes avanços na área oncológica, o diagnóstico do câncer tem usualmente um efeito devastador, afeta e abala a integridade psicológica do paciente. É um momento gerador de intensa angústia em geral, associada ao estigma da doença de uma época que não havia tratamento disponível e a possibilidade da morte era eminente.

Hoje o câncer é considerado uma doença crônica e absolutamente tratável e em muitos casos a cura está presente. Mesmo assim continua sendo uma doença estigmatizada, carregada de preconceito e mistério, estimuladora de fantasias irracionais.

Essa situação de sofrimento conduz a uma problemática psíquica com características específicas. A literatura relata que existem variáveis psicológicas que influenciam no prognóstico da doença que compromete significativamente a vida do indivíduo nos aspectos biológicos, social, emocional, exigindo assistência especializada de diferentes profissionais.

Essa atuação não deve restringir-se a múltiplos profissionais que atuam isoladamente, mas deve ser uma real integração na compreensão dos problemas e na proposição de intervenções para auxiliar o indivíduo no restabelecimento do seu bem estar.

O aparecimento da doença rompe a rotina da criança e do adolescente, alterando toda uma dinâmica de vida calcada em atividades escolares, sociais e familiares. 
O diagnóstico de uma leucemia consiste no surgimento de uma situação de crise para o paciente, que terá então, que encontrar recursos para enfrentá-la.

Essa crise trará uma série de conseqüências tais como:

1-desestruturação do sistema biopsicossocial do indivíduo;

2-interrupção no processo de desenvolvimento psicosexual e intelectual;

3-regressões a estágios primitivos do desenvolvimento;

4-reações emocionais de luto;

5-intensificações das angústias de morte, levando á mobilizações de defesas psicológicas;

6-redirecionamento das energias para adaptação á realidade hospitalar, aos procedimentos e hospitalizações.

Diante de todas essas mudanças, a criança reage de diferentes maneiras: períodos de isolamento, depressão, intelectualização. Ocorre a busca constante de objetos protetores que passam amenizar seus temores. Sente-se desprotegida e ameaçada diante de novos procedimentos ou mudanças no tratamento.

Se não consegue elaborar essas situações, angústia depressiva e defesas psicológicas inadequadas podem ser mobilizadas e interferir no seu desenvolvimento psicosocial, na aprendizagem e nos relacionamentos interpessoais.

As fases descritas por Elizabeth Rubler Ross, em seu livro "Sobre a Morte e o Morrer" (1988), negação, raiva, barganha, depressão e aceitação, são frequentemente encontradas em crianças e adolescentes vivenciam o processo de adoecer.

Os meios de enfrentar o problema e com ele conviver depende da estrutura da personalidade da criança, das relações com familiares e com as pessoas ao seu redor.

A criança ou adolescente que recebeu o diagnóstico de leucemia ou aquele que já recebeu este diagnóstico, mas se curou da doença, demonstra sentir-se extremamente limitado e frequentemente ameaçado pela possibilidade de recaída. Estas ameaças e limitações tornam a adolescência um período de vida repleto de conflitos em função da discrepância entre o impulso por novas descobertas e busca por independência, e as inúmeras restrições que cercam o jovem em função da situação da paciente em tratamento. 
Adolescência costuma ser citada como um tempo de perdas físicas e psicológicas. As chamadas mortes simbólicas do corpo infantil de algum tipo de relacionamento ou atividades devido às transformações.

Nesses casos é importante considerar qual transformação é devido à fase evolutiva e qual é devido à doença.

Diante de todas essas transformações e sentimentos o adolescente vivencia uma situação de crise necessitando de assistência do acompanhamento psicológico, promovendo assistência para que ele possa encontrar condições para o enfrentamento da doença com qualidade de vida.

A psicologia pode ser uma chave para compreensão do câncer no individuo através da participação do psicólogo numa equipe multiprofissional sendo possível resgatar a dimensão psicológica do adoecer, do tratamento e da assistência. 


\section{Hemocentro de Marília e o Ambulatório de Onco-Hemato-Infantil}

O hemocentro da Famema é uma das 04 unidades que compõem a Faculdade de Medicina de Marília, iniciou suas atividades em 1991. Atua como Centro de Referência em Hematologia para a região oeste e centro oeste do Estado de São Paulo, atendendo uma população superior a 2.000.000 habitantes distribuídos em 110 municípios.

Atualmente é responsável pelo abastecimento de 6 grandes Agencias Transfusionais de Marilia: Hospital de Clinicas, Hospital Materno Infantil, Santa Casa de Misericórdia, Hospital São Francisco, Maternidade Gota de Leite e Hospital Universitário, além de 14 agências transfusionais de municípios vizinhos de Marilia.

Atende em média 21.600 doadores de sangue por ano e realiza um número médio de transfusões é de 1959/mês.

Além do atendimento hemoterápico específico atua com $\mathrm{o}$ atendimento hematológico sendo que no ambulatório de onco-hemato-infantil foi implantado o serviço de atendimento psicológico que se encontra em funcionamento desde 1994. Durante este período foram atendidos pelo ambulatório 3.840 pacientes (1994 à 12/2007), destes 3825 foram encaminhados para avaliação psicológica. O ambulatório de atendimento psicológico tem crescido em função da melhora de diagnóstico, da procura por serviços de referência e da formação atualizada de equipe multiprofissional. Dentro da atuação psicoterápica de base analítica, a identificação, acompanhamento e intervenção da depressão e do estresse da criança e do adolescente constitue forte aliado ao tratamento multidisplinar do paciente onco-hematológico.

\section{Depressão Infantil}

Os transtornos depressivos constituem um grupo de patologias com alta e crescente prevalência na população geral. Conforme a Organização Mundial de Saúde haverá nas próximas duas décadas uma mudança dramática nas necessidades de saúde da população mundial, devido ao fato de que doenças como depressão e cardiopatias estão substituindo os tradicionais problemas das doenças infecciosas e de má nutrição. Considera-se que a 
depressão maior na infância e na adolescência apresenta natureza duradoura e pervasiva, afeta múltiplas funções e causa significativos danos psicossociais (Rev.de pediatria, 1996).

$\mathrm{Na}$ atualidade, os transtornos depressivos em crianças e adolescentes e aqueles em adultos são compreendidos como entidades fenomenológicas iguais, fato derivado de pesquisas que definiram que os mesmos critérios diagnósticos são confiavelmente aplicados nestas três faixas etárias. Segundo o Manual Diagnóstivo e Estatístico de Transtornos Mentais (DSM-IV) (J.Psychoson, 1996) os sintomas básicos de um episódio depressivo maior (Quadro 1 ) são os mesmos em adultos, adolescentes e crianças, embora existam dados sugerindo que a predominância de sintomas característicos pode mudar com a idade, citando sintomas muito comuns em crianças (queixas somáticas, irritabilidade e retraimento social) e sintomas menos comuns em crianças (retardo psicomotor, hipersonia e delírios). Já a Classificação Internacional das Doenças (CID-10) lida com os transtornos depressivos de forma idêntica em todos os grupos etários, com apenas a seguinte citação específica “apresentações atípicas são particularmente comuns no episódio depressivo na adolescência", mas não fornece maiores esclarecimentos.

\begin{tabular}{|ll|}
\hline Quadro 1 - Sintomas do episódio depressivo maior - DSM-IV \\
\hline 1. & Humor deprimido ou irritável \\
\hline 2. & Interesse ou prazer acentuadamente diminuidos \\
\hline 3. & Perda ou ganho significativo de peso, ou diminuição ou aumento do apetite \\
\hline 4. & Insonia ou hipersonia \\
\hline 5. & Agitação ou retardo psicomotor \\
\hline 6. & Fadiga ou perda de energia \\
\hline 7. & Sentimento de inutilidade ou culpa excessiva ou inadequada \\
\hline 8. & Capacidade diminuida de pensar ou concentrar-se ou indecisão \\
\hline 9. & Pensamentos de morte recorrentes, ideação suicida, tentativa ou plano suicida \\
\hline & Fonte: Orgone Psicologia Clinica; artigo: Transtornos do Humor. \\
\hline
\end{tabular}

A maioria dos autores na área dos transtornos depressivos na infância e adolescência cita que os sintomas variam com a idade, destacando a importância do processo de maturação das diferentes fases do desenvolvimento nos sintomas e comportamentos depressivos, existindo uma caracterização sintomatológica predominante por faixa etária. 
Em crianças pré-escolares (idade até seis a sete anos), a manifestação clínica mais comum é representada pelos sintomas físicos, tais como dores (principalmente de cabeça e abdominais), fadiga e tontura. Goodyer(1996) cita que aproximadamente $70 \%$ dos casos de depressão maior em crianças apresentam queixas físicas. As queixas de sintomas físicos são seguidas por ansiedade (especialmente ansiedade de separação), fobias, agitação psicomotora ou hiperatividade, irritabilidade, diminuição do apetite com falha em alcançar o peso adequado, e alterações do sono. Alguns autores ainda citam, com menor freqüência, a ocorrência de enurese e encoprese, fisionomia triste, comunicação deficiente, choro freqüente, movimentos repetitivos e auto e heteroagressividade na forma de comportamento agressivo e destrutivo. O prazer de brincar ou ir para a pré-escola diminui ou desaparece e as aquisições de habilidades sociais próprias da idade não ocorrem naturalmente (Quadro 2). Embora a maioria dos autores afirma que neste período não ocorrem ideação ou tentativas de suicídio, Shafii e Shaffi (1997) destacam que o comportamento autodestrutivo na forma de bater a cabeça severa e repetidamente, morder-se, engolir objetos perigosos e a propenção a acidentes pode ser um equivalente suicida em crianças que não verbalizam emoções. Entretanto, a ideação suicida nesta faixa etária é considerada de ocorrência rara, podendo ocorrer em casos especiais. Quanto às famílias, estudos norte-americanos realizados com crianças pré-escolares com depressão encontraram freqüentemente pais também com depressão e envolvidos em graves problemas sociais.

\begin{tabular}{|ll|}
\hline Quadro & $\mathbf{2}$ - Sintomas de depressão em crianças pré-escolares \\
\hline 1. & Dores ( de cabeça e abdominais) \\
\hline 2. & Prazer de brincar e ir à pré-escola diminuído \\
\hline 3. & Dificuldade na aquisição de habilidades sociais da idade \\
\hline 4. & Ansiedade \\
\hline 5. & Fobias \\
\hline 6. & Agitação ou hiperatividade \\
\hline 7. & Irritabilidade \\
\hline 8. & Diminuição do apetite \\
\hline 9. & Alterações do sono \\
\hline Fonte: Jornal de Pediatria, Rio de Janeiro, 2002.
\end{tabular}

Em crianças escolares (idade entre seis a sete anos até doze anos), o humor depressivo já pode ser verbalizado e é freqüentemente relatado como tristeza, irritabilidade ou tédio. Apresentam aparência triste, choro fácil, apatia, fadiga, isolamento, declínio ou 
desempenho escolar fraco, podendo chegar à recusa escolar, ansiedade de separação, fobias e desejo de morrer. Também podem relatar concentração fraca, queixas somáticas, perda de peso, insônia e sintomas psicóticos humor-congruente (alucinações auditivas depreciativas e, menos freqüentemente, delírios de culpa e pecado). O declínio no desempenho pode dever-se à fraca concentração ou interesse, próprios do quadro depressivo. É comum a criança não ter amigos, dizer que os colegas não gostam dela ou apresentar um apego exclusivo e excessivo a animais. Inabilidade em se divertir (anedonia), pobre relacionamento com seus pares e baixa autoestima, se descrevendo como estúpidas, bobas ou impopulares também podem estar presentes (Quadro 3 $)$.

\begin{tabular}{|ll|}
\hline Quadro 3 - Sintomas de depressão em crianças escolares \\
\hline 1. & Tristeza, irritabilidade e/ou tédio \\
\hline 2. & Falta de habilidade em se divertir \\
\hline 3. & Aparência triste \\
\hline 4. & Choro fácil \\
\hline 5. & Fadiga \\
\hline 6. & Isolamento com fraco relacionamento com seus pares \\
\hline 7. & Baixa auto-estima \\
\hline 8. & Declínio ou desempenho escolar fraco \\
\hline 9. & Ansiedade de separação \\
\hline 10. & Fobias \\
\hline 11. & Desejo ou fantasias de morte \\
\hline
\end{tabular}
Fonte: Jornal de Pediatria, Rio de Janeiro, 2002.

Tanto em crianças pré-escolares como nas escolares a depressão pode tornar-se clara através da observação dos temas das fantasias, desejos, sonhos, brincadeiras e jogos, com os conteúdos predominantes de fracasso, frustração, destruição, ferimentos, perdas ou abandonos, culpa, excesso de autocríticas e morte.

A manifestação da depressão em adolescentes (idade a partir de doze anos) costuma apresentar sintomas semelhantes aos dos adultos, mas também existem importantes características fenomenológicas que são típicas do transtorno depressivo nesta fase da vida. Adolescentes deprimidos não estão sempre tristes; apresentam-se principalmente irritáveis e instáveis, podendo ocorrer crises de explosão e raiva em seu comportamento. Segundo Kazdin e Marciano (2002), mais de 80\% dos jovens deprimidos apresentam humor irritado e ainda perda de energia, apatia e desinteresse importante, retardo psicomotor, sentimentos 
de desesperança e culpa, perturbações do sono, principalmente hipersonia, alterações de apetite e peso, isolamento e dificuldade de concentração. Outras características próprias desta fase são o prejuízo no desempenho escolar, a baixa auto-estima, as idéias e tentativas de suicídio e graves problemas de comportamento, especialmente o uso abusivo de álcool e drogas. O desenvolvimento do pensamento abstrato se faz ao redor dos doze anos de idade, trazendo uma compreensão mais clara do fenômeno da morte, conseqüentemente, nos adolescentes depressivos tanto as idéias de suicídio como as tentativas, que costumam apresentar alta letalidade, alcançam uma dimensão maior, pois os adolescentes são altamente vulneráveis às mesmas (Quadro 4 ).

\begin{tabular}{|ll|}
\hline Quadro 4 - Sintomas de depressão em adolescentes \\
\hline 1. & Irritabilidade e instabilidade \\
\hline 2. & Humor deprimido \\
\hline 3. & Perda de energia \\
\hline 4. & Desmotivação e desinteresse importante \\
\hline 5. & Retardo psicomotor \\
\hline 6. & Sentimentos de desesperança e/ou culpa \\
\hline 7. & Alterações do sono \\
\hline 8. & Isolamento \\
\hline 9. & Ansiedade de separação \\
\hline 10. & Dificuldade de concentração \\
\hline 11. & Baixa auto-estima \\
\hline 12. & Idéias e tentativas de suicídio \\
\hline 13. Problemas graves de comportamento \\
\hline
\end{tabular}

\section{Estresse Infantil}

Segundo Lipp e Romano (1987), o estresse infantil assemelha-se ao do adulto em vários aspectos, podendo gerar sérias conseqüências, no caso de ser excessivo. A reação da criança frente a eventos excitantes, irritantes, felizes, amedrontadores, ou seja, que exijam adaptação por parte dela, inclui mudanças psicológicas, físicas e químicas no seu organismo.

É reconhecido que experiência de estresse severo na infância podem produzir resultados psicofisiologicos duradouros, que podem perdurar na vida adulta. (Udwing, 1993). Quando a criança é exposta a um evento estressante, seja ele bom ou ruim, ela entra em estado de alerta, ocorrendo assim uma ativação do sistema nervoso simpático e da 
glândula pituitária, por meio do hipotálamo. Ao mesmo tempo, ocorre a ativação das glândulas supra renais que liberam adrenalina, preparando a criança para a reação de "luta e fuga" e provocando a inibição das atividades vegetativas, o que pode ocasionar mudanças nos hábitos alimentares (perda do apetite) e alteração do sono.

Lipp e Romano (1987) descrevem, a partir de observações clinicas, os sintomas do stress infantil que, assim como no adulto podem ser psicológicos, físicos ou ambos. Segundo estas autoras, as reações ao estresse infantil, também, são divididas em psicológicas e físicas:

Possíveis efeitos psicológicos: ansiedade, terror noturno, pesadelos, dificuldades interpessoais, introversão súbita, desanimo, insegurança, agressividade, choro excessivo, angustia, depressão, hipersensibilidade, birra e medo excessivo.

Possíveis sensações físicas: dores abdominais, diarréia, tique nervoso, dor de cabeça, náusea, hiperatividade, enurese noturna, gagueira, tensão muscular, bruxismo, dificuldade para respirar e transtornos alimentares.

Dos sintomas mencionados, alguns podem ser considerados como mais evidentes, porque são mais facilmente identificados ou observados, como pesadelos, medos, choro excessivo e dores abdominais; outros são mais obscuros, como sentimento de alienação e introversão súbita, e podem dificultar a percepção do stress na criança.

Cástes-Boscan e Pocino (2000) relatam que o estresse induz respostas fisiológicas anormais, que ocorrem após o processamento da situação conflitante, pelo sistema nervoso central. Para eles, a resposta do organismo frente a essa situação, ocorrerá conforme sua interpretação, que se baseia no estado do indivíduo naquele momento, e em suas experiências passadas.

O estresse, em princípio, não é uma doença. É apenas a preparação do organismo para lidar com as situações que surgem, sendo então uma resposta a um determinado estímulo, o qual varia de pessoa para pessoa. O prolongamento ou a exacerbação de uma situação específica, é que de acordo com as características do indivíduo, naquele momento, podem gerar alterações indesejáveis (DAVIS, 1996).

$\mathrm{O}$ estresse infantil pode se originar de causas ou fontes externas ou internas, (LIPP, et al.,1991). A autora ainda descreve, com base em observações clínicas, que os sintomas do stress infantil, assim como nos adultos, são manifestações, exteriorizações de pressões e 
tensões sobre a criança e o adolescente e, que podem ser de ordens psicológicas, físicas ou ambas.

As causas internas são criadas pela própria criança, ou seja, dependem da forma como ela reage diante de situações do seu dia-a-dia, de seus pensamentos (cognição) e do tipo de personalidade.

Como fontes internas de estresse na criança, a autora cita: ansiedade; depressão; timidez; desejo de agradar; medo de fracasso; preocupação com mudanças físicas; medo de punição divina; dúvidas quanto à própria inteligência; à própria beleza etc.; interpretações amedrontadas de eventos simples; medo de os pais morrerem e ela ficar só; medo de que alguém morra porque sua morte foi desejada em momentos de briga; medo de ser ridicularizada por amigos; sentir-se injustiçada sem ter como se defender; desacordo entre as exigências de sucesso e o verdadeiro potencial. (LIPP, 1991).

A situação de doença foi caracterizada por Lipp et al. (1991), como uma causa externa do estresse infantil. Isto porque a criança vive um período de muita angústia e sofrimento determinado por fatores como: ambiente desconhecido, medidas terapêuticas invasivas, retirada do ambiente familiar, convívio com outros que estão na mesma situação, apresentando quadros semelhantes ou até piores, onde elas podem apresentar irritabilidade ou retraimento.

Os fatores de maior ou menor vulnerabilidade ao stress na infância são diretamente influenciados pelas diversas formas de apoio social que a criança recebe, principalmente dos pais, recursos internos e habilidades que ela possui em seu repertório, para lidar com os agentes que provocam o estresse (LAZARUS, 1966; ELLIS, 1973).

Simonton e Creighton (1987) pressupõem que o câncer é uma doença que diz respeito à pessoa como um todo, incluindo o corpo e a mente, e não simplesmente um fato isolado, idéia que ainda persiste em alguns meios científicos. Estes, afirmam que o câncer surge como uma indicação de problemas existentes em outras áreas da vida da pessoa, agravados ou compostos de uma série de estresse que surgem de 6 a 18 meses antes do aparecimento da doença.

Segundo Leshan (1992) "no período que antecede a instalação do câncer, ou seja, antes dos primeiros sinais da proliferação caótica celular, existe um padrão de perda da 
esperança em $70 \%$ a $80 \%$ das pessoas que adoecem, enquanto apenas $10 \%$ apresentam esse comportamento no grupo em que inexistia a doença".

Castro e Piccinini (2002), afirmam que a doença crônica pode ser vista como fonte de stress, que afeta o desenvolvimento normal da criança e atinge as relações sociais dentro do sistema familiar.

Quando o câncer aparece em uma criança, provoca brusca interrupção no seu desenvolvimento. $\mathrm{O}$ afastamento do ambiente doméstico e escolar torna-se necessário, em função de longos períodos de internação, provocando, em muitos casos, a desorganização do mundo interno da criança e de seus cuidadores. Devido a todas as novidades inseridas no seu cotidiano (medicamentos, exames, consultas e diversos procedimentos invasivos), a criança vivencia novas sensações, tais como: medo, sensação de punição, despersonalização, regressão no seu desenvolvimento psicológico e cognitivo (CAMON, 1997; CHIATTONE, 2003).

Além da dor causada por esses procedimentos, a quimioterapia e a radioterapia trazem o agravante dos efeitos colaterais, responsáveis por freqüentes reinternações e por sofrimentos que, embora não tragam a dor física, geram danos afetivos e emocionais, como no caso da alopécia (MENOSSI e LIMA, 2000).

As náuseas e vômitos, decorrentes da quimioterapia, causam incômodo e estresse, podendo determinar conseqüências metabólicas (perda de secreções estomacais e intestinais), psicossociais (incapacidade de executar tarefas habituais), comportamentais e fisiológicas (anorexia e depleção nutricional), que podem causar infecções, caquexia e morte (GRANT, sd). Portanto, a prevenção e o controle destes sintomas, são de fundamental importância para melhorar a qualidade de vida do paciente e para o sucesso do tratamento.

A ruptura com a escola também se constitui problema para estes pacientes, causada pelo próprio tratamento, por ocasião das internações prolongadas. É importante, que um acompanhamento escolar formal, seja mantido durante o processo de hospitalização, ou seja, um vínculo escola/hospital para que a vida escolar possa seguir seu curso.

Os afastamentos temporários da escola, sejam eles breves ou prolongados, muitas vezes, podem fazer com que a criança venha a sentir-se excluída, de umas das atividades 
de aprendizagem mais importante para o seu desenvolvimento cognitivo (VANCE e EISER, 2002).

Além disso, se o tratamento não produz resultados imediatos, e a doença evolui para estágios mais graves, surgem outras formas de sofrimento: dor física causada pela própria doença; medo da morte e medidas terapêuticas dolorosas (como punções, drenagens, entubações).

Estes aspectos podem ser potencializados, pela gravidade da doença e agressividade do tratamento, podendo desencadear nas crianças e adolescentes, reações de stress, como: retraimento, apatia, choro, irritabilidade, entre outras (LIPP, 1991).

Os sintomas mais comuns em crianças menores que sofrem de câncer são os sintomas de estresse e ansiedade. Isso é explicado por uma série de fatores, como o rebaixamento da auto-estima, a insegurança em relação a seu futuro e as dúvidas sobre a possibilidade de superar a doença sem seqüelas e assim, dar continuidade a seu projeto de vida (RONA e VARGAS, 1994).

Entre as principais causas de sofrimento de adolescentes com câncer, Menossi e Lima (2000), encontraram a hospitalização, a restrição nas atividades cotidianas, a terapêutica agressiva, a alteração da auto-imagem e o medo da morte.

Parry (2003) menciona em seus estudos, que mesmo com um crescente aumento nas taxas de sobrevivência do câncer infantil, o sentimento de incerteza permanece presente na vida de muitos sobreviventes, após o término do tratamento, prejudicando sua adaptação psicossocial, o que constitui em ameaça ao seu bem estar.

A doença interfere de alguma forma, em pelo menos três aspectos da vida: o biológico, o social e o psicológico, e estes, juntos ou isoladamente, influenciarão na qualidade de vida da criança, do adolescente, e de sua família, tornando-se uma situação geradora de estresse, exigindo capacidade de adaptação mental e física.

\section{Intervenção Psicológica em pacientes oncológicos}

Para compreender fundamentalmente as repercussões emocionais dos pacientes diante do diagnóstico de câncer e indicação cirúrgica, partimos da noção psicanalítica de que a emoção acompanha o ser humano desde o seu primeiro contato com o meio e o influencia ao longo da vida. As emoções interagem com todo e qualquer fenômeno do 
desenvolvimento humano promovendo a responsabilidade do homem pela própria história. Evidencia-se, portanto, a relevância de se olhar a doença para além da noção de uma etiologia específica e a de integrá-la à compreensão dos aspectos psicológicos, culturais, sociais, entre outros. Psique e soma não podem ser vistos de forma separada, as emoções precisam ser mobilizadas para que os estados afetivos não sejam camuflados.(SCHESTATSKY, 2005)

É essencial compreender, ouvir e aprender com o paciente, tendo sempre em mente que estamos cuidando de um ser humano e não apenas da enfermidade que ele traz.

Intervir para a melhor forma de enfrentamento de doença e reduzir os sintomas emocionais diante do processo de adoecer, proporcionando o paciente a compreender o significado da experiência do adoecer, e o re-significado deste processo, possibilitando o desenvolvimento de estratégias para enfrentar as situações estressantes e o manejo dessas situações, num espaço de acolhimento e escuta, onde o terapeuta deve trabalhar com a realidade. Quanto mais informações o paciente tiver de sua doença, maior será sua capacidade de enfrentar o adoecer e mais confiante ficará em relação à equipe e na aderência ao tratamento.

O foco da intervenção psicoterápica de base analítica, de maneira geral, esta voltado para o processo de adoecer e nas preocupações do pensamento, visando um atendimento humanizado e global ao paciente, buscando a compreensão do significado simbólico da doença e dos conflitos emocionais inconscientes ligados ao processo de adoecer.(EIZIRIK, 2005)

A intervenção psicoterapêutica à crianças portadoras de doença grave consiste em ajudá-los a elaborar as experiências de perda decorrentes do adoecimento por meio do trabalho de luto. Este é um aspecto essencial do atendimento psicoterapêutico, dado que muitos sintomas psicológicos afetam significativamente a capacidade psicológica para o crescimento e desenvolvimento criativo do self. (Klein, 1969)

No que tange a abordagem psicoterápica com crianças, um referencial possível seria aquele que implicaria a aceitação do uso do brinquedo. A criança se expressa pelo brinquedo, comunicando seus conflitos intrapsiquicos e atualizando aspectos de suas primitivas relações objetais no setting terapêutico. A observação da conduta da criança 
durante a sessão permite identificar a ansiedade, o estresse predominante, a depressão, as defesas mobilizadas e os impulsos.

Em psicoterapia de orientação é crucial ter-se em mente as diferentes formas de comunicação da criança de acordo com a idade, dadas as suas condições motoras, perceptivas, cognitivas e de linguagem. (Prego e Silva, 1990)

A psicoterapia analítica de crianças respeita as diferenças marcantes quanto a técnica, variando de acordo com as peculiaridades da criança, um ser em evolução. No entanto, no caso de uma criança com câncer, sua evolução e as comunicações podem ser alteradas em função da doença e tratamento.

Os sentimentos mobilizados como medo ansiedade, depressão e estresse, podem trazer significativa alteração em sua conduta ou comportamento, comunicando o seu desconforto de maneira expressiva e peculiar.

Nesse sentido o terapeuta, necessita acessar com boa acuidade o mundo interno da criança estando suas intervenções voltadas às suas capacidades cognitivas, seus recursos egóicos, respeitando, contudo o momento vivenciado com o adoecer.

A psicoterapia analítica de crianças respeita as diferenças marcantes quanto a técnica, variando de acordo com as peculiaridades da criança, um ser em evolução. No entanto no caso de uma criança com câncer, a expressão lúdica do conflito será determinada pelo momento pelo desenvolvimento da criança, as intervenções do terapeuta deveram ser acessíveis às capacidades cognitivas da mesma. Quanto mais simples, breves e objetivas forem as intervenções maiores serão as possibilidades de insigth da criança.

A psicoterapia de orientação psicanalítica bem como a psicanálise se vale da comunicação expressiva do terapeuta, que é, por excelência, a interpretação. Porem há uma gama de intervenções que vão desde a interpretação ate ao encorajamento e a validação empática, de acordo com a terapêutica.

Com o uso das intervenções, o terapeuta pode amenizar os sentimentos de ansiedade, depressão e estresse vivenciados pela criança, contribuindo significativamente para um processo de melhora integral em sua qualidade de vida.

$\mathrm{O}$ uso do brinquedo proporciona o afloramento das emoções, facilita a intervenção do terapeuta, que busca decodificar o que é expresso pela criança, diante do enfrentamento, com características saudáveis, no contexto da situação de saúde-doença. 


\section{Justificativa}

Partindo da experiência da atuação na clinica psicológica no ambulatório de doenças onco-hematológicas infantil do Hemocentro da Faculdade de Medicina de Marília (FAMEMA), surgiu o interesse em compreender o processo do adoecer na criança e adolescente com câncer, cujo tratamento é repleto de vivencias de sofrimento e dor, e impõe para quem o enfrenta, uma grande ameaça à sua integridade física e psíquica.

Justifica-se o desenvolvimento do presente trabalho, pois, é evidente o crescimento do número de pacientes onco-hemato-infantil para acompanhamento psicológico. Outro fator relevante é que praticamente não há investigações sobre intervenção psicoterápica de modelo analítico em crianças e adolescentes em tratamento onco-hematológico com sintomas depressivos e de estresse. 


\section{OBJETIVOS}

\subsection{OBJETIVOS GERAL}

Avaliar os efeitos da intervenção psicoterápica de modelo analítico (IPS) para crianças de ambos os sexos, com doenças onco-hematológicas infantil, em tratamento no Ambulatório de onco-hemato-infantil pediátrica do Hemocentro de Marília.

\subsection{OBJETIVOS ESPECÍFICOS}

Avaliar à redução de níveis de estresse e de depressão por meio de intervenção psicoterápica de modelo analítico (IPS) em pacientes atendidos no ambulatório de oncohemato-infantil do Hemocentro de Marília. 


\section{CASUÍSTICA E MÉTODOS}

\subsection{Casuística}

O universo de pacientes onco-hemato-infantil encaminhados pelo Ambulatório Onco-hemato-infantil do Hemocentro de Marília para atendimento psicológico, na ocasião do início das coletas de dados e intervenções psicológicas do estudo, a partir de março de 2009, foi de 13 crianças e adolescentes portadoras de doenças onco-hematógicas.

Constituíram a amostra deste estudo, sete crianças, sendo quatro do sexo feminino e três do sexo masculino. A idade média foi de 8,7 anos completos e desvio-padrão de 2,4 anos completos; mediana de 8 anos completos; idade mínima de 7 anos completos e idade máxima de 14 anos completos (Tabela 1).

Foram excluídas do estudo uma participante do sexo feminino que foi a óbito, um bebe, e três com idade inferior às recomendadas para responderem ao Inventário de Depressão Infantil (CDI) - 7 anos e a Escala de Stress Infantil (ESI) - 6 anos.

Tabela 1 - Caracterização dos participantes, considerando sexo, idade, escolaridade e diagnóstico. Cada participante é representado pela letra $\mathrm{P}$ (com a finalidade de manter o sigilo do participante), acompanhado de um número indicador da ordem de entrada no estudo.

\begin{tabular}{ccccc}
\hline PACIENTE & IDADE & SEXO & ESCOLAR & DIAGNÓSTICO \\
\hline P1 & 9 & $\mathrm{~F}$ & $3 \mathrm{SEF}^{1}$ & LLA $^{2}$ \\
P2 & 8 & $\mathrm{~F}$ & $2 \mathrm{SEF}$ & LLA \\
P3 & 8 & $\mathrm{M}$ & $3 \mathrm{SEF}$ & LLA \\
P4 & 7 & $\mathrm{~F}$ & $1 \mathrm{SEF}$ & LLA \\
P5 & 7 & $\mathrm{~F}$ & $1 \mathrm{SEF}$ & NEUROBLASTOMA \\
P6 & 14 & $\mathrm{M}$ & $7 \mathrm{SEF}$ & LLA \\
P7 & 8 & $\mathrm{M}$ & 2 SEF & LLA \\
\hline 'SEF $=$ SÉRIE DO ENSINO FUNDAMENTAL & ${ }^{2}$ LLA $=$ & Leucemia linfóide aguda
\end{tabular}

\subsection{Desenho do estudo}


Trata-se de um ensaio clínico não-randomizado intra-grupos de séries temporais, no qual a intervenção foi realizada com um único grupo e os desfechos foram comparados em cada participante durante diferentes períodos desta intervenção (HULLEY et al., 2003).

\subsection{Desenvolvimento, local e período do estudo}

Os participantes foram avaliados por meio de instrumentos psicológicos (CDI e ESI) em cinco momentos: pré-teste T0D (antes da intervenção psicológica - IPS), pós-teste T30D (30 dias após primeira etapa da IPS), pós-teste T60D (30 dias após segunda etapa da IPS), pós-teste T90D (30 dias após terceira etapa da IPS) e pós-teste T120D (30 dias após quarta etapa da IPS) (Quadro 1).

Quadro 5 - Desenvolvimento do ensaio clínico não-randomizado intra-grupos de séries temporais, no qual a intervenção foi realizada com um único grupo e quatro intervenções psicológicas (IPS1, IPS2, IPS3, IPS4)

\begin{tabular}{|c|c|c|c|c|c|c|c|c|c|}
\hline & TOD $^{1}$ & IPS & T30D $^{2}$ & IPS & T60D $^{3}$ & IPS & T90D $^{4}$ & IPS & $\mathrm{T120D}^{5}$ \\
\hline $\begin{array}{l}\text { Coleta } \\
\text { de } \\
\text { dados }\end{array}$ & $\begin{array}{l}\text { CDI0D } \\
\text { ESI0D }\end{array}$ & IPS1 & $\begin{array}{l}\text { CDI30D } \\
\text { ESI30D }\end{array}$ & IPS2 & $\begin{array}{l}\text { CDI60D } \\
\text { ESI60D }\end{array}$ & IPS3 & $\begin{array}{l}\text { CDI90D } \\
\text { ESI90D }\end{array}$ & IPS4 & $\begin{array}{l}\text { CDI120D } \\
\text { ESI120D }\end{array}$ \\
\hline
\end{tabular}

O estudo foi realizado no Hemocentro de Marília - FAMEMA, no período de agosto de 2008 a novembro de 2009.

\subsection{Instrumentos}

\section{Inventário de Depressão Infantil (CDI) (ANEXO A):}

Dentre os inventários de auto-avaliação relatados na literatura, o CDI ou Inventário de Depressão Infantil tem sido o instrumento mais comum na identificação de sintomas depressivos. O Children's Depression Inventory (CDI) foi o primeiro instrumento elaborado para estudar os sintomas de depressão na infância. O CDI foi proposto por Kovacs em 1983 (KOVACS, 1992), e surgiu de uma adaptação do BDI - Beck Depression Inventory. Tratase de uma escala de auto-avaliação de 27 itens, destinada a identificar os sintomas de depressão em crianças e tem sido largamente utilizada em estudos epidemiológicos internacionais e brasileiros. 
No Brasil, o CDI foi adaptado para a população brasileira por Gouveia et al. (1995) e tem sido muito empregado como medida de sintomas depressivos em crianças e adolescentes escolares de 7 a 17 anos. O inventário avalia sintomas afetivos, cognitivos e comportamentais da depressão e é composto por 20 questões. De acordo com os autores, o CDI é um instrumento com parâmetros psicométricos aceitáveis, sendo bastante útil na identificação de crianças depressivas.

Cada item possui três alternativas de resposta. O paciente é orientado a selecionar a alternativa que melhor descreve a intensidade de seus sentimentos durante as duas últimas semanas sendo que a alternativa com resposta 0 (ZERO) corresponde à ausência de sintomas, 1(UM) presença do sintoma e 2(DOIS) sintoma grave.

O ponto de corte é a soma das respostas de forma que a criança/adolescente com pontuação igual ou superior a 17 pontos deverá merecer atenção, uma vez que tal resultado pode indicar um provável quadro depressivo (GOUVEIA et al., 1995).

O objetivo deste instrumento é avaliar a presença e a gravidade do transtorno depressivo, identificando alterações afetivas em crianças e adolescentes, não sendo um instrumento diagnóstico.

\section{Escala de Estresse Infantil (ESI) (ANEXO B)}

A escala de Estresse Infantil é composta de 35 itens que tem por objetivo fornecer qualidades psicométricas quanto à identificação dos sintomas do stress na criança (LIPP; LUCARELLI, 1998). A apuração das respostas é feita através da contagem de pontos atribuída a cada item, cada quarto de círculo equivalendo a um ponto. A partir da contagem dos pontos, pode-se dizer que a criança avaliada tem stress quando os resultados forem: aparecimento de 7 ou mais itens com círculos totalmente preenchidos; ou nota maior ou igual a 27 pontos nos itens relacionados às reações físicas RF (itens: 2, 6, 12, 15, 17, 19, 21, 24 e 34); ou nota maior ou igual a 27 pontos nos itens relacionados às reações psicológicas RP (itens 4, 5, 7, 8, 10,11, 26, 30 e 31); ou nota maior ou igual a 27 pontos às reações psicológicas com componente depressivo RPCD (itens: 13, 14, 20, 22, 25, 28, 2932 e 35); ou nota maior ou igual a 24 pontos nos itens relacionados às reações psicofisiológicas RPF (itens: $1,3,9,16,18,23,27$ e 33); ou nota total da escala maior que 105 pontos. O estudo 
demonstrou que estas são as reações ligadas ao stress que cada item é capaz de medir. Sendo assim, há a possibilidade de verificar a existência ou não de stress em crianças e adolescentes, além de determinar o tipo de reação mais freqüente, o que facilitará o controle adequado do stress.

A situação de doença foi caracterizada por Lipp et at. (1991), como uma causa externa do estresse infantil.

Isto porque a criança vive um período de muita angustia e sofrimento determinado por fatores como: ambiente desconhecido, medidas terapêuticas invasivas, retirada do ambiente familiar, convívio com outros que estão na mesma situação, apresentando quadros semelhantes ou ate piores, onde elas podem apresentar irritabilidade ou retraimento.

A Escala de Stress Infantil- ESI surgiu do interesse em validar o Inventário de Sintomas de Stress Infantil (Lipp e Romano, 1987) pela sua aplicabilidade nas diferentes áreas de atuação do psicólogo e por estar sendo, amplamente utilizada em pesquisas nesta área. Ela tem como objetivo verificar ou não a existência de estresse em crianças da faixa etária de seis (6) a 14 anos, e possibilita ainda que se determine o tipo de reação mais freqüente nos respondentes.

\subsection{Coleta de dados}

Procedeu-se a caracterização demográfica do grupo estudado com idade, sexo, escolaridade diagnóstica.

As avaliações foram feitas antes e após a intervenção, com dia local e horário previamente marcado; sendo as avaliações realizadas na sala da psicologia do hemocentro onde também se realizaram as intervenções terapêuticas psicológicas.

O período de coleta de dados foi de agosto de 2008 a novembro de 2009. 


\subsection{Intervenção Psicoterapêutica -IPS}

A intervenção Psicológica é caracterizada pelo atendimento clínico da criança ou adolescente em sessões com tempo médio de 40 minutos, sendo que no T0 o responsável (pai, mãe, tio e avós) são entrevistados conjuntamente com o paciente. Nos T30, 60 e 120 respectivamente, a IPS é feita forma individual. Após o estabelecimento da recepção do menor de forma a colocá-lo à vontade na consulta, outras atividades são utilizadas para o afloramento das emoções: brinquedos, montagem de Lego®, atividades de desenhos e pinturas, massa de modelar e jogos variados. Durante o período de ludoterapia as informações fluem de forma natural evidenciando as angústias, dúvidas, fobias, sentimentos de perda, etc. A periodicidade da IPS foi de no mínimo 7 dias e no máximo 10 dias. Isto se fez necessário em função da compatibilidade da IP e dos protocolos de quimioterapia ou radioterapia que o mesmo estava fazendo. Em muitas ocasiões, intervenções suplementares foram realizadas a pedido do paciente, ou família ou ainda equipe assistente. Os instrumentos de pesquisa foram aplicados apenas nos dias de registro. No intervalo, observações gerais sobre o paciente eram registradas. Após leitura das questões dos questionários para a criança, o pesquisador registrou a resposta mais adequada.

\subsection{Procedimentos}

Inicialmente foi estabelecido o contato com o Departamento de Ensino e Pesquisa da Instituição que foi avaliado o projeto no Comitê de Ética em Pesquisa envolvendo Seres Humanos da FAMEMA, visando o consentimento para a realização do estudo. Após a aprovação, foi efetuada a seleção dos sujeitos. Estabeleceu se o contato com as crianças, os adolescentes, e seus responsáveis, para solicitar o consentimento pessoal dos mesmos, para a participação da pesquisa, garantindo a confidencialidade das informações.

Este trabalho foi norteado pelos princípios éticos de respeito e sigilo, visando à proteção dos envolvidos na pesquisa, conforme a Resolução 196/96 e assinatura de Consentimento Livre e Esclarecido. O estudo foi conduzido após aprovação do Comitê de Ética em Pesquisa em Seres Humanos da FAMEMA, Marília, SP, parecer processo 
158/2009. Os responsáveis de todos os pacientes assinaram o termo de consentimento livre e esclarecido (TCLE) (APÊNDICE A).

Após o esclarecimento aos participantes e responsáveis e a assinatura do TCLE, os participantes foram submetidos à IPS de acordo com a rotina do tratamento.

A aplicação dos inventários foram realizados de forma individual, na sala da psicologia do Hemocentro da Faculdade de Medicina de Marília. De acordo com os agendamentos dos participantes, os questionários foram aplicados em cinco momentos: T0D (após diagnostico), T30D (trinta dias de tratamento), T60D (após 60 dias de tratamento), T90D (após 90 dias de tratamento) e T120D (após 120 dias de tratamento).

\subsection{Análise dos dados}

Teste de correlação de Spearmann ( $\mathrm{r}_{\mathrm{S}}$ ) para o estudo das correlações entre idade, escores CDI e escores ESI (RF, RP, RPCD e RPF) nos momentos T0D, T30D, T60D, T90D e T120D. Para a avaliação qualitativa do $\mathrm{r}_{\text {Spearmann }}$ quanto a sua intensidade, utilizou7-se o critério descrito no quadro a seguir, segundo Callegari-Jacques (2003, p.173; p.90):

Quadro 6 - Avaliação qualitativa do grau de correlação entre duas variáveis.

\begin{tabular}{|c|c|}
\hline$\left|\mathbf{r}_{\text {Spearman }}\right|$ & A correlação é dita \\
\hline 0 & Nula \\
\hline $0-0,3$ & Fraca \\
\hline $0,3[-0,6$ & Regular \\
\hline $0,6[-0,9$ & Forte \\
\hline $0,9[-1$ & Muito forte \\
\hline 1 & Plena ou perfeita \\
\hline
\end{tabular}

Adotou-se em todos os testes de correlações o nível de significância de $5 \%$ de probabilidade para a rejeição da hipótese de nulidade. 


\section{Inventário CDI}

Os indivíduos participantes do estudo serão analisados individualmente, segundo o momento do estudo (T0D, T30D, T60D, T90D E T120D), a partir do escore CDI total $($ CDIT $=$ soma dos escores das respostas dos 20 itens), classificando-se cada indivíduo, considerando-se o ponto de corte correspondente à soma das respostas, em cada momento, de forma que a criança/adolescente com pontuação igual ou superior a 17 pontos deverá merecer atenção, uma vez que tal resultado, pode indicar um provável quadro depressivo (GOUVEIA et al., 1995).

Também será calculado o nível de melhora \% - CDI, do momento final (T120D) em relação ao momento inicial (T0D), obtido pela seguinte equação (E1):

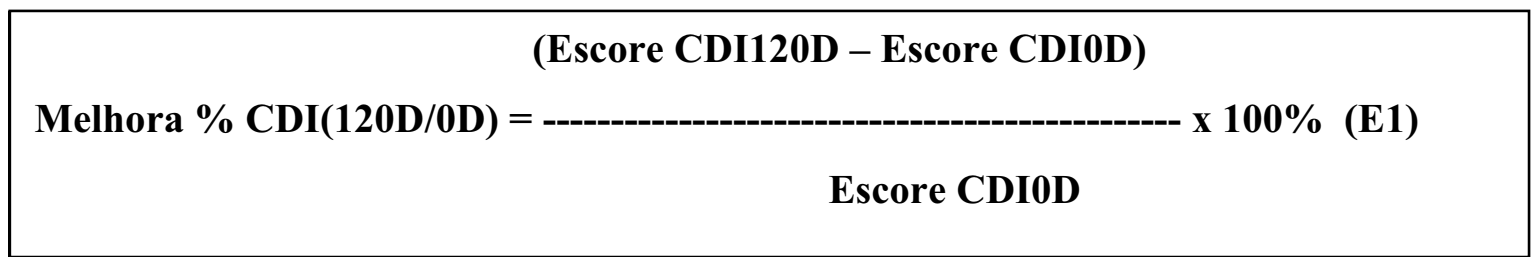

Deve-se observar que o sinal negativo no porcentual indica melhora (para o inventário CDI quanto menor de 17 o escore CDI for e mais próximo de 0 menos provável de indicar um quadro depressivo), no entanto deve-se também levar em conta a classificação do participante de modo que a criança/adolescente com pontuação igual ou superior a 17 pontos deverá merecer atenção, uma vez que tal resultado pode indicar um provável quadro depressivo (GOUVEIA et al., 1995).

\section{Escala de Stress Infantil (ESI)}

Com relação aos dados obtidos para a Escala ESI, estes foram analisados somandose os pontos e estabelecendo o escore total e os escores das reações avaliada (físicas $=\mathrm{RF}$, psicológica $=\mathrm{RP}$, psicológicas com componente depressivo $=\mathrm{RPCD}$ e psicofisiológica $=\mathrm{RPF}$ ), fazendo a classificação da fase de estresse que a criança/adolescente se encontravam. Essa classificação foi realizada de acordo com o Manual da Escala de Stress Infantil e segundo 
os critérios recomendados para diagnóstico do stress infantil, em cada uma das fases: Fase de Alerta, Fase de resistência, Fase de Quase-Exaustão e Fase de Exaustão e do escore total da escala (ESI) (ANEXO D) (LIPP, LUCARELLI; 2005).

Foi calculado para cada participante o nível de Melhora \% ESI, do momento final (T120D) em relação ao momento inicial (T0D), obtido pela seguinte equação (E2):

\section{[Escore ESI120D(final) - Escore ESI0D(inicial)]}

Melhora\%ESI = $\times 100 \%(E 2)$

\section{Escore ESI0D(inicial)}

Deve-se observar que o sinal negativo no porcentual indica melhora, no entanto deve-se também levar em conta a classificação ESI do participante realizada de acordo com o Manual da Escala de Stress Infantil e segundo os critérios recomendados para diagnóstico do stress infantil, em cada uma das fases: Fase de Alerta, Fase de resistência, Fase de Quase-Exaustão e Fase de Exaustão e do escore total da escala (ESI). 


\section{RESULTADOS E DISCUSSÃO}

\subsection{INVENTÁRIO DE DEPRESSÃO INFANTIL (CDI)}

$\mathrm{Na}$ avaliação qualitativa observou-se o desempenho dos escores individualmente levando em consideração aquele determinado no momento do início das intervenções psicológicas (IPS). A figura abaixo representa o escore de cada um dos 7 pacientes. A análise dos escores CDI ao final do período das intervenções registra uma melhora no estado geral dos sintomas de depressão dos participantes (escores finais aos 120 dias inferiores a 17) (Tabela 2 e Figura 1).

Tabela 2 - Apresentação dos resultados qualitativos obtidos com o escore total padronizado do CDI, caracterizados por normal (NORMAL) ou atenção a sintomas depressivos (ATENÇÃO)

\begin{tabular}{c|c|c|c|c|c}
\hline Paciente & CDI0D & CDI30D & CDI60D & CDI90D & CDI120D \\
\hline P1 & ATENÇÃO & ATENÇÃO & ATENÇÃO & ATENÇÃO & NORMAL \\
\hline P2 & ATENÇÃO & ATENÇÃO & ATENÇÃO & NORMAL & NORMAL \\
\hline P3 & ATENÇÃO & ATENÇÃO & ATENÇÃO & ATENÇÃO & NORMAL \\
\hline P4 & NORMAL & NORMAL & NORMAL & NORMAL & NORMAL \\
\hline P5 & NORMAL & NORMAL & NORMAL & NORMAL & NORMAL \\
\hline P6 & ATENÇÃO & NORMAL & NORMAL & NORMAL & NORMAL \\
\hline P7 & NORMAL & NORMAL & NORMAL & NORMAL & NORMAL \\
\hline $\begin{array}{c}\text { GRUPO } \\
\text { Mediana) }\end{array}$ & ATENÇÃO & NORMAL & NORMAL & NORMAL & NORMAL \\
\hline
\end{tabular}




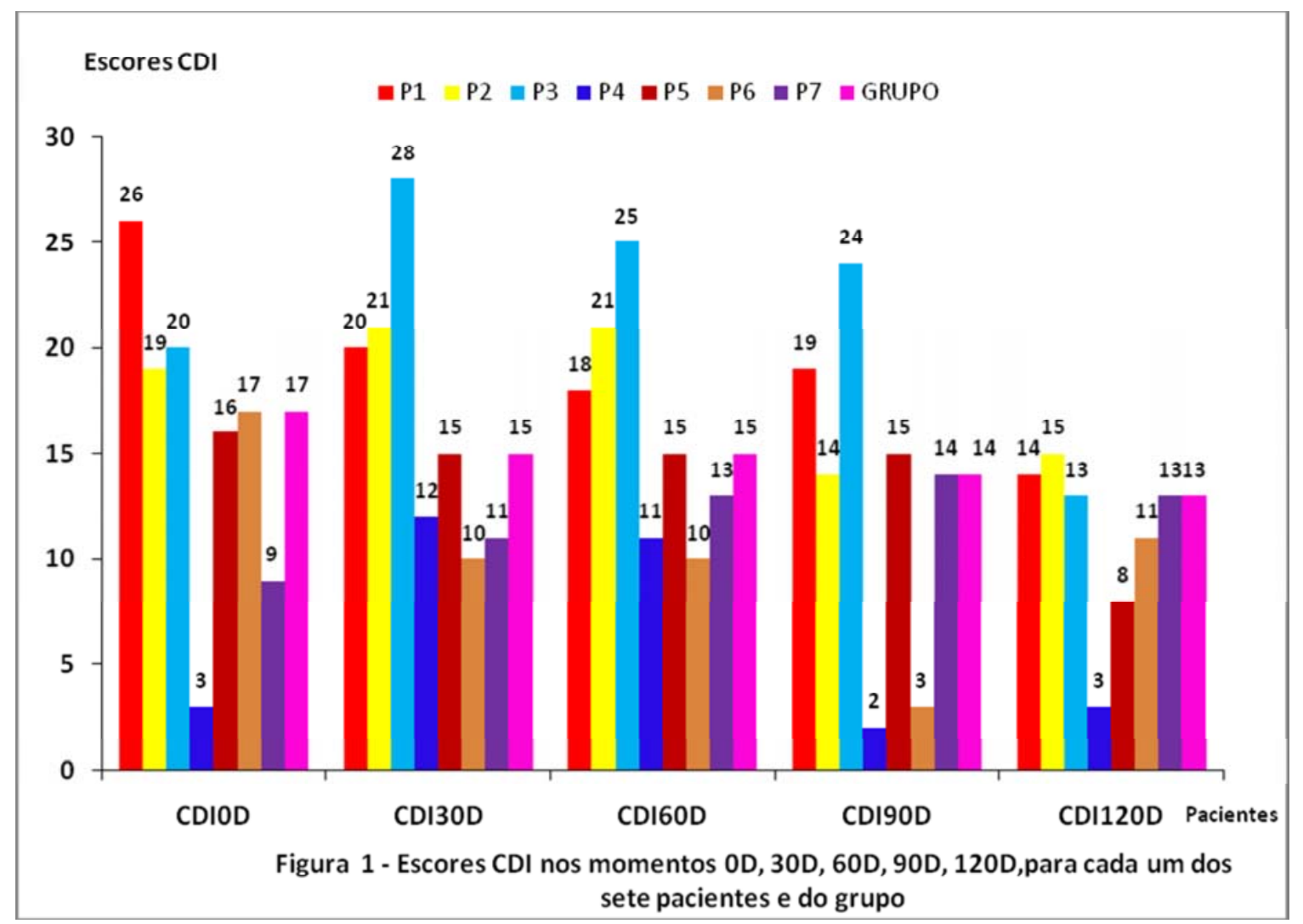

Na Figura 2 observa-se uma melhora ao final das intervenções em relação ao momento inicial do estudo para os pacientes P1, P2, P3, P5 e P6, sendo classificados ao final do período das IPS como normais. Não foi identificada modificação no escore de estresse do paciente $\mathrm{P} 4$, e houve modificação nos escores do paciente $\mathrm{P} 7$, no entanto ambos não apresentando quadro de sintomas de depressão (escores menores que 17).

Levando-se em conta a avaliação qualitativa do CDI, observou-se que os indivíduos apresentavam normalidade para os sintomas de depressão no final do seguimento(T120) apresentando escores inferiores a 17 em T120, ou seja, saíram do estado de alerta para sintomas depressivos. Estes sintomas relacionam-se com o sofrimento que envolve a hospitalização, também está relacionado às internações não planejadas, devido à intercorrências inesperadas. Estas internações geralmente são decorrentes de complicações, como as infecções, as alterações no diagnóstico e os casos de recidiva da doença. $\mathrm{Na}$ realidade este fato destaca que é efetivamente após o início dos efeitos secundários da 
quimioterapia e radioterapia, que os efeitos depressivos se instalam frente a constatação da perda do cabelo, hemorragias freqüentes, adinamia, incapacidade de brincar ou limitação para tal. Em todos os pacientes foi observado melhora, exceto para P7. Esta piora deve encontrar justificativa nas complicações médicas que o mesmo apresentou acrescido das turbulências que afetavam o núcleo familiar, porém a sua classificação CDI foi normal.

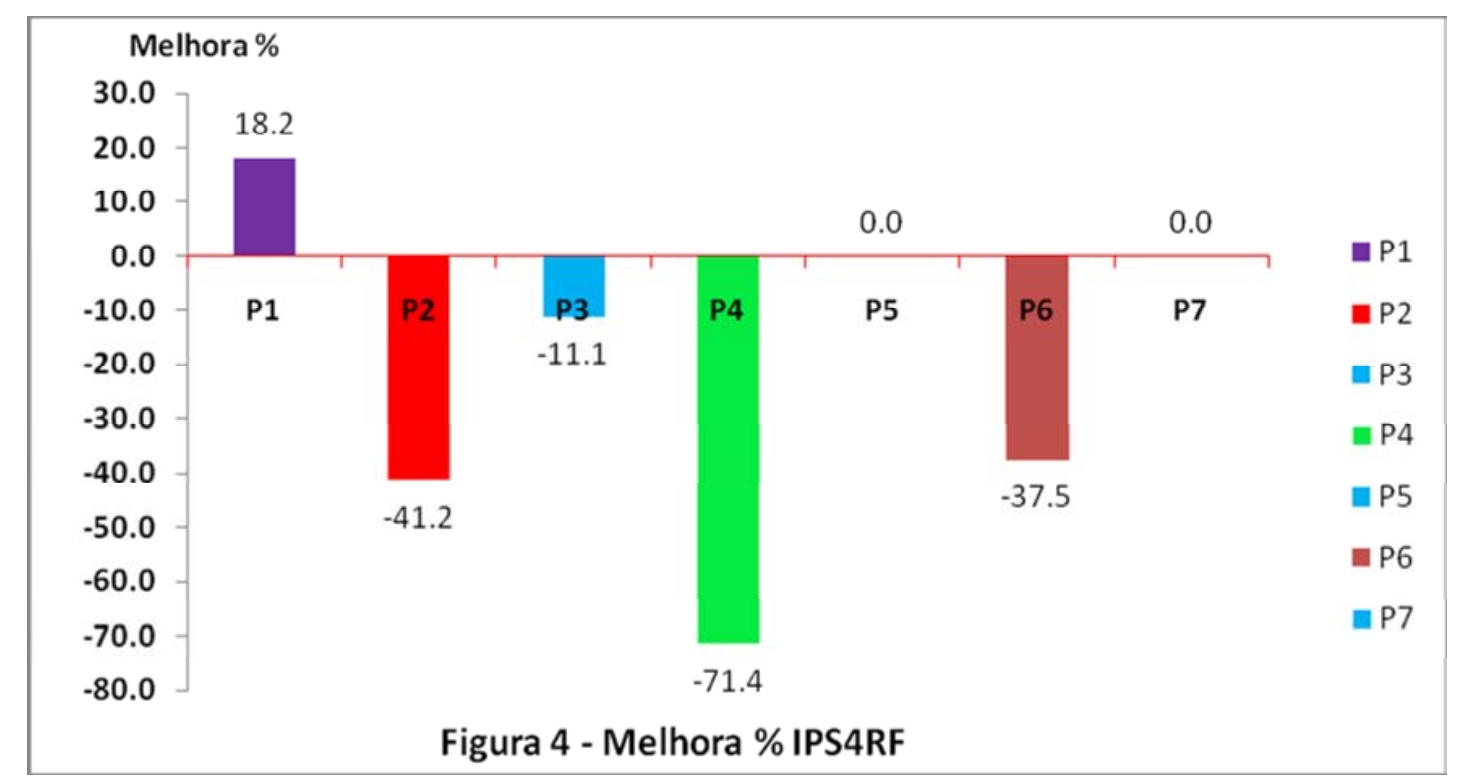

\subsection{ESCALA DE ESTRESSE INFANTIL (ESI)}

A avaliação dos escores ESI foram realizadas levando-se em conta as reações: físicas (RF), psicológicas (RP), psicológicas com componente depressivo e psicofisiológicas (RPF), fazendo a classificação da fase de stress em que os participantes se encontravam.

\section{REAÇÕES FÍSICAS (RF)}


Quando se analisa o percentual de melhora do escore do estresse infantil quando se leva em consideração a variável: reações físicas, observa-se que para os pacientes P2, P3, P4 e P6, houve registro de melhora.

O paciente P1, que no inventário de depressão teve desempenho satisfatório com melhora percentual dos escores, no inventário de estresse quanto às reações físicas registrou fase transitória de estresse (alerta).

Para o paciente P5, que no CDI houve melhora expressiva do percentual dos escores, identifica-se que o mesmo não apresentou reações físicas de estressou durante o tratamento. Este paciente apresenta núcleo familiar sólido, solidário, presente fatos estes estabilizadores da resposta emocional (Tabela 3 e Figura 3).

O paciente $\mathrm{P} 7$ apresentou classificação normal tanto no CDI como nas RF da ESI.

Tabela 3 - Apresentação dos resultados qualitativos obtidos com o escore padronizado da ESI, caracterizados por fases, sendo estas: normal, alerta, resistência e stress, segundo as reações físicas (RF)

\begin{tabular}{c|c|c|c|c|c}
\hline Paciente & RF0D & RF30D & RF60D & RF90 & RF120D \\
\hline P1 & ALERTA & ALERTA & NORMAL & NORMAL & ALERTA \\
\hline $\mathbf{P 2}$ & RESISTÊNCIA & RESISTÊNCIA & ALERTA & ALERTA & ALERTA \\
\hline $\mathbf{P 3}$ & NORMAL & NORMAL & NORMAL & NORMAL & NORMAL \\
\hline $\mathbf{P 4}$ & NORMAL & NORMAL & NORMAL & NORMAL & NORMAL \\
\hline $\mathbf{P 5}$ & NORMAL & NORMAL & NORMAL & NORMAL & NORMAL \\
\hline P6 & NORMAL & NORMAL & NORMAL & NORMAL & NORMAL \\
\hline P7 & NORMAL & NORMAL & NORMAL & NORMAL & NORMAL \\
\hline
\end{tabular}




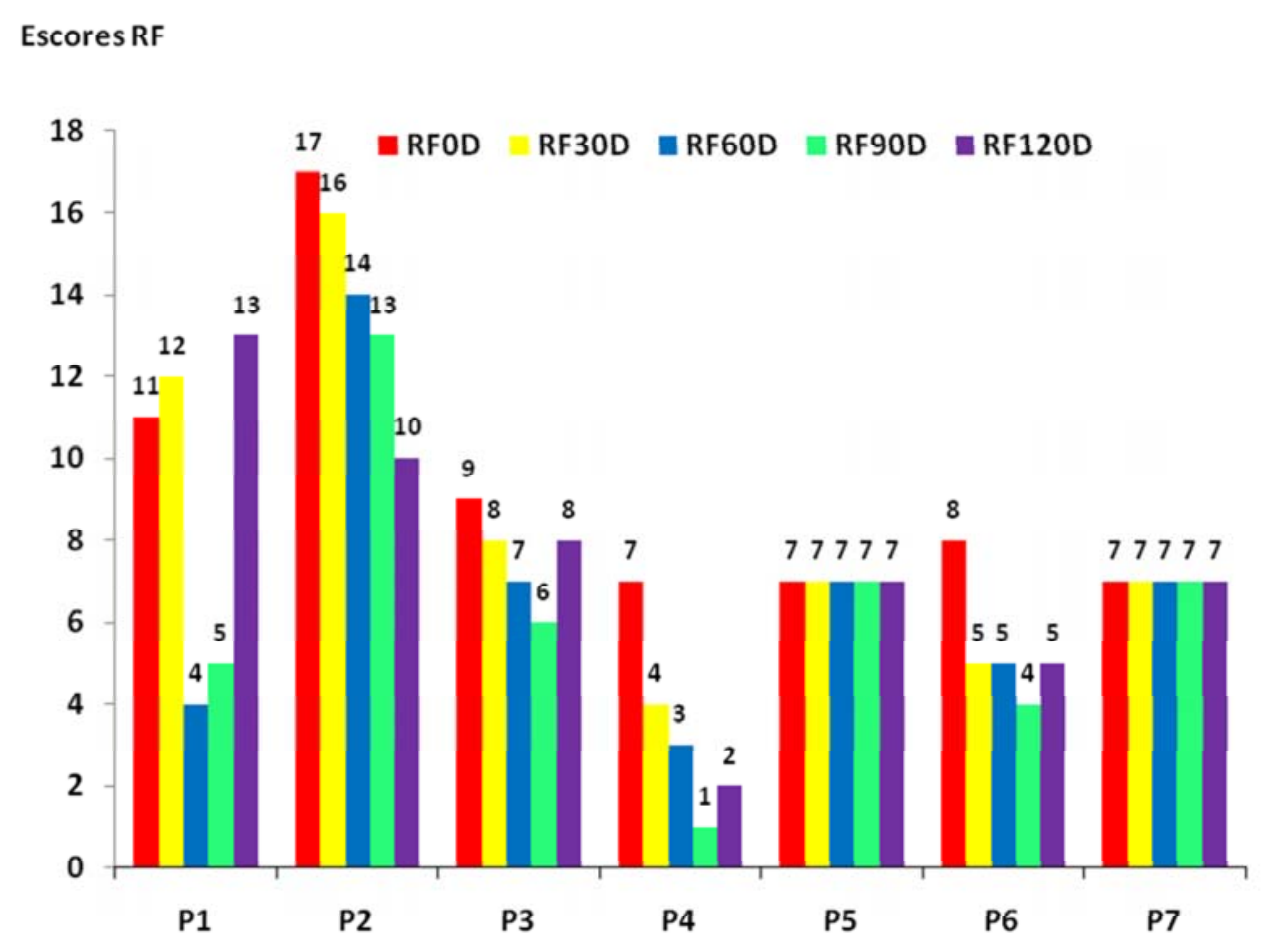

Figura 3 - Escores RF0D, RF30D, RF60D, RF90D e RF120D dos pacientes P1, P2, P3, P4, P5, P6 e P7

A Figura 4 registra a melhora porcentual dos pacientes entre a intervenção psicológica inicial e final levando-se em consideração as RF. Houve melhora para 4 pacientes, P2, P3, P4 e P6.

O paciente P1 inicialmente alerta em RF, apresentou uma piora porcentual, devido a um aumento no escore RF em T120, porém ainda classificado como alerta (Figura 3 e Figura 4).

Os pacientes P5 e P7 não apresentaram melhora porcentual, pois permaneceram classificados normais em RF em todos os momentos (Figura3 e Figura 4). 


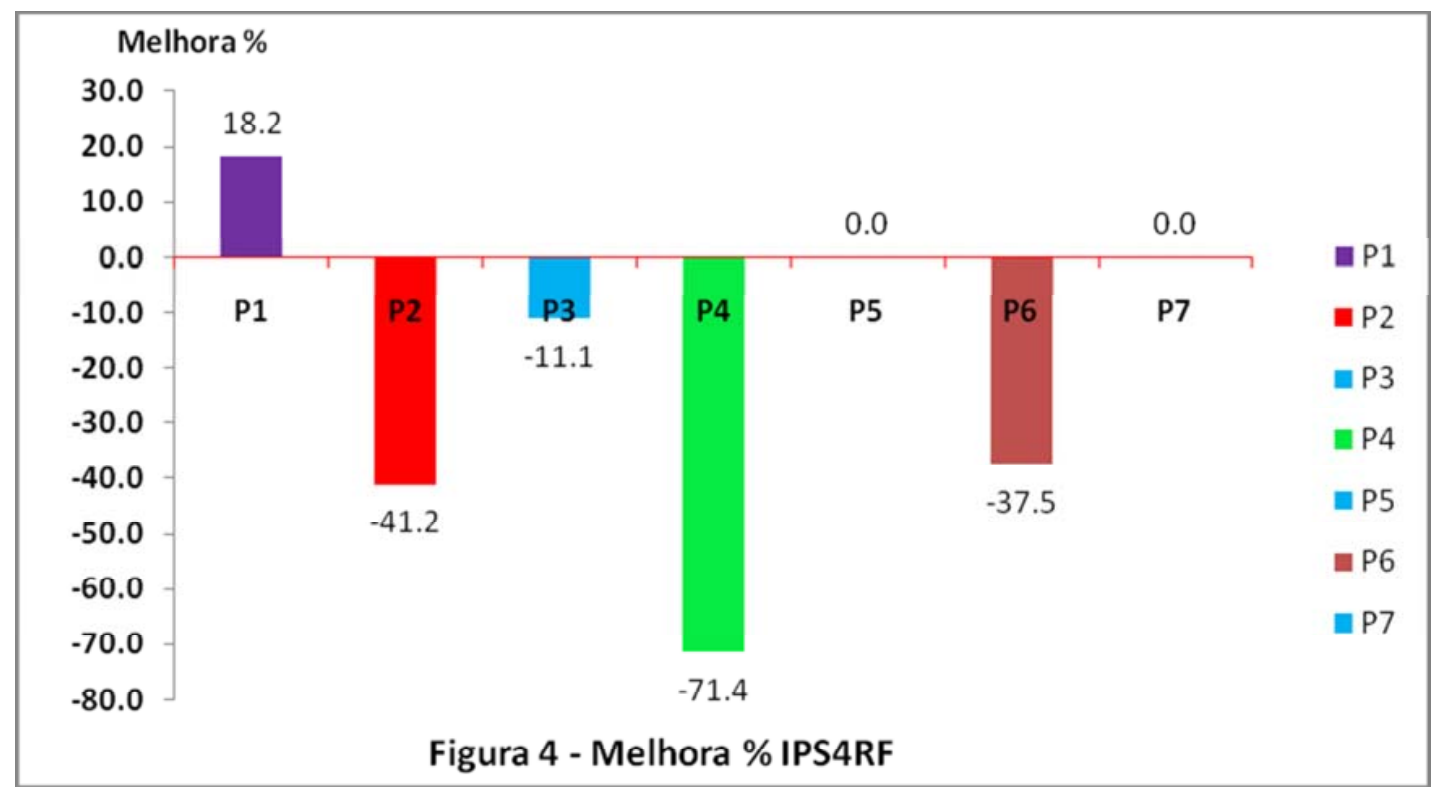

\section{REAÇÕES PSICOLÓGICAS (RP)}

Quando se analisa o escore do estresse infantil levando em consideração a variável: reações psicológicas observa-se que para os pacientes P2, P3 e P6, houve registro de melhora final em relação ao início.

$\mathrm{O}$ paciente $\mathrm{P} 1$, no inventário de estresse quanto às reações psicológicas registrou fase transitória de estresse (alerta), no início e T120.

Para os pacientes P5 e P7, identifica-se fase de resistência, excesso de fontes de estresse em todos os momentos para as reações psicológicas (Tabela 4 e Figura 5).

Tabela 4 - Apresentação dos resultados qualitativos obtidos com o escore padronizado da ESI, caracterizados por fases, sendo estas: normal, alerta, resistência e stress, segundo as reações psicológicas (RP)

\begin{tabular}{l|l|l|l|l|l}
\hline Paciente & RP0D & RP30D & RP60D & RP90 & RP120D \\
\hline $\mathbf{P 1}$ & ALERTA & NORMAL & RESISTENCIA & ALERTA & ALERTA \\
\hline $\mathbf{P 2}$ & QUASE- & QUASE- & QUASE- & REISTENCIA & RESISTENCIA \\
& EXAUSTÃO & EXAUSTÃO & EXAUSTÃO & & \\
\hline $\mathbf{P 3}$ & ALERTA & ALERTA & ALERTA & NORMAL & NORMAL \\
\hline $\mathbf{P 4}$ & NORMAL & NORMAL & NORMAL & NORMAL & NORMAL \\
\hline $\mathbf{P 5}$ & RESISTENCIA & RESISTENCIA & RESISTENCIA & RESISTENCIA & RESISTENCIA \\
\hline $\mathbf{P 6}$ & ALERTA & ALERTA & NORMAL & NORMAL & NORMAL \\
\hline $\mathbf{P 7}$ & RESISTENCIA & RESISTENCIA & RESISTENCIA & RESISTENCIA & RESISTENCIA \\
\hline
\end{tabular}




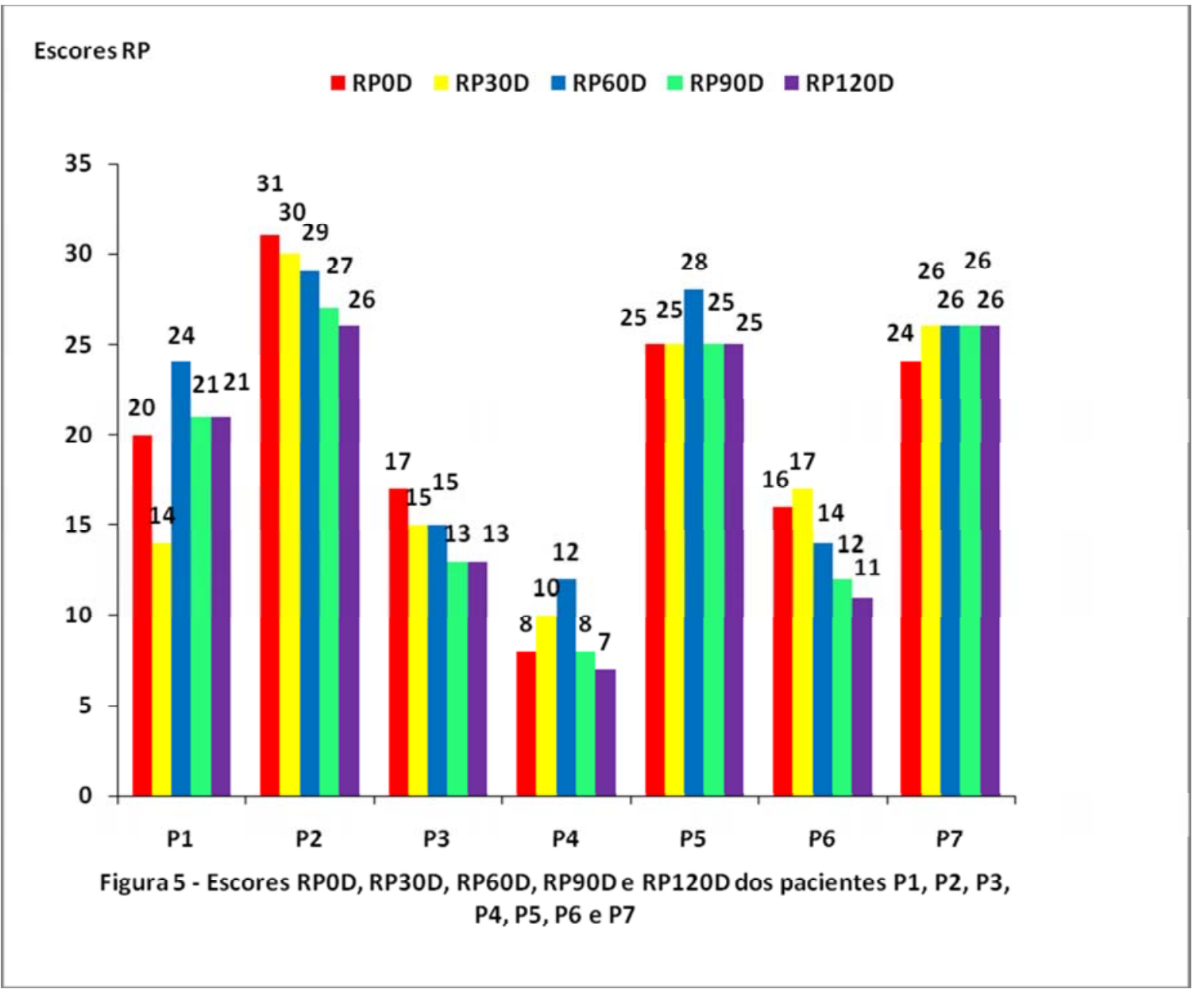

A Figura 6 registra a melhora porcentual dos pacientes entre a intervenção psicológica inicial e final levando-se em consideração as RP. Houve melhora para 4 pacientes, P2, P3, P4 e P6.

Os pacientes P1 e P7, inicialmente alerta em RP, apresentaram uma piora porcentual, devido a um aumento no escore RP em T120, porém ainda classificados como alerta (Figura 5 e Figura 6).

O paciente P5 e não apresentou melhora porcentual, pois permaneceu classificado normal em RP em todos os momentos (Figura5 e Figura 6). 


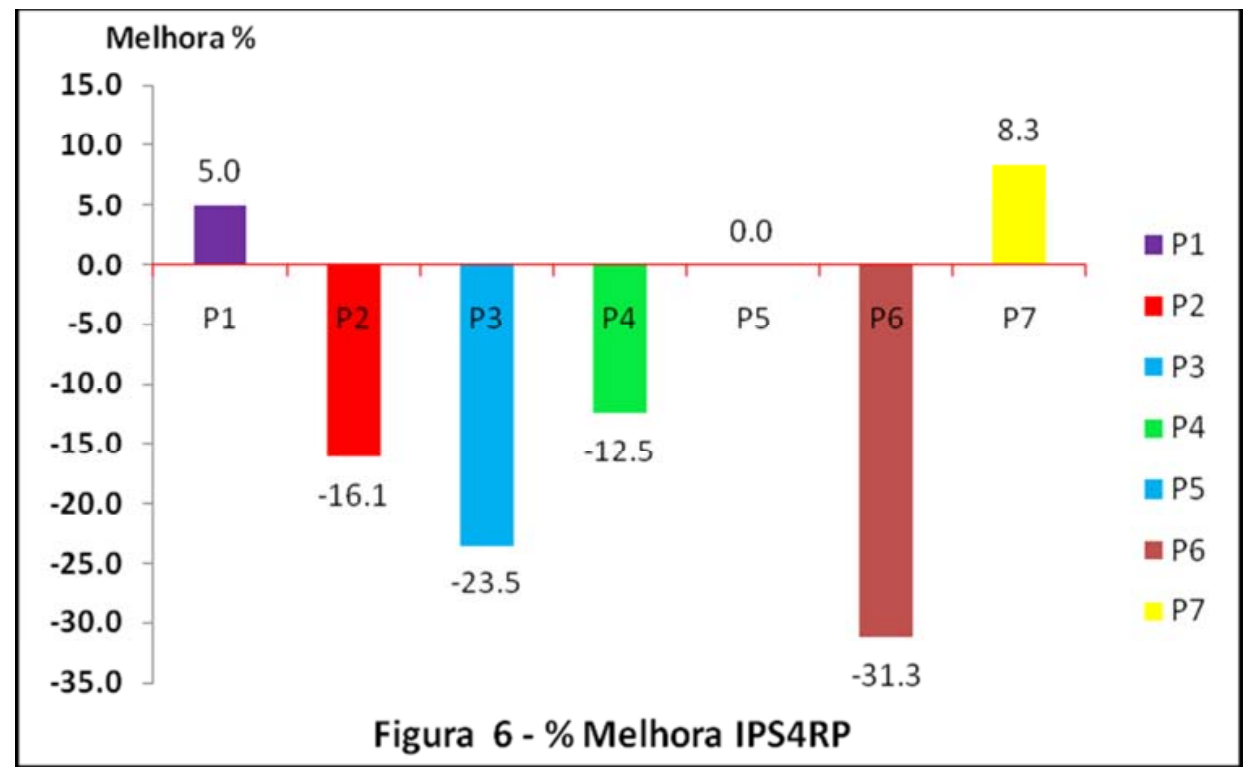

\section{REAÇÕES PSICOLÓGICAS COM COMPONENTE DEPRESSIVO (RPCD)}

Quando se analisa o escore do estresse infantil levando em consideração a variável: reações psicológicas com componente depressivo observa-se que somente para o paciente P1 houve registro de melhora final em relação ao início. Para os pacientes P2, P5 e P7, identificam-se fase transitória de estresse, alerta, em todos os momentos para as RPCD.

Para o paciente P3, identifica-se fase de resistência, excesso de fontes de estresse em todos os momentos para as RPCD. Os pacientes P4 e P6 foram classificados como normal, não apresentando estresse infantil em nenhum momento para as RPCP (Tabela 5 e Figura 7).

Tabela 5- Apresentação dos resultados qualitativos obtidos com o escore padronizado da ESI, caracterizados por fases, sendo estas: normal, alerta, resistência e stress, segundo as reações psicológica com componente depressivo (RPCD)

\begin{tabular}{l|l|l|l|l|l}
\hline Paciente & RPCD0D & RPCD30D & RPCD60D & RPCD90 & RPCD120D \\
\hline P1 & ALERTA & ALERTA & NORMAL & NORMAL & NORMAL \\
\hline P2 & ALERTA & ALERTA & ALERTA & ALERTA & ALERTA \\
\hline $\mathbf{P 3}$ & RESISTENCIA & RESISTENCIA & RESISTENCIA & RESISTENCIA & RESISTENCIA \\
\hline $\mathbf{P 4}$ & NORMAL & NORMAL & NORMAL & NORMAL & NORMAL \\
\hline $\mathbf{P 5}$ & ALERTA & ALERTA & ALERTA & ALERTA & ALERTA \\
\hline $\mathbf{P 6}$ & NORMAL & NORMAL & NORMAL & NORMAL & NORMAL \\
\hline $\mathbf{P 7}$ & ALERTA & ALERTA & ALERTA & ALERTA & ALERTA \\
\hline
\end{tabular}




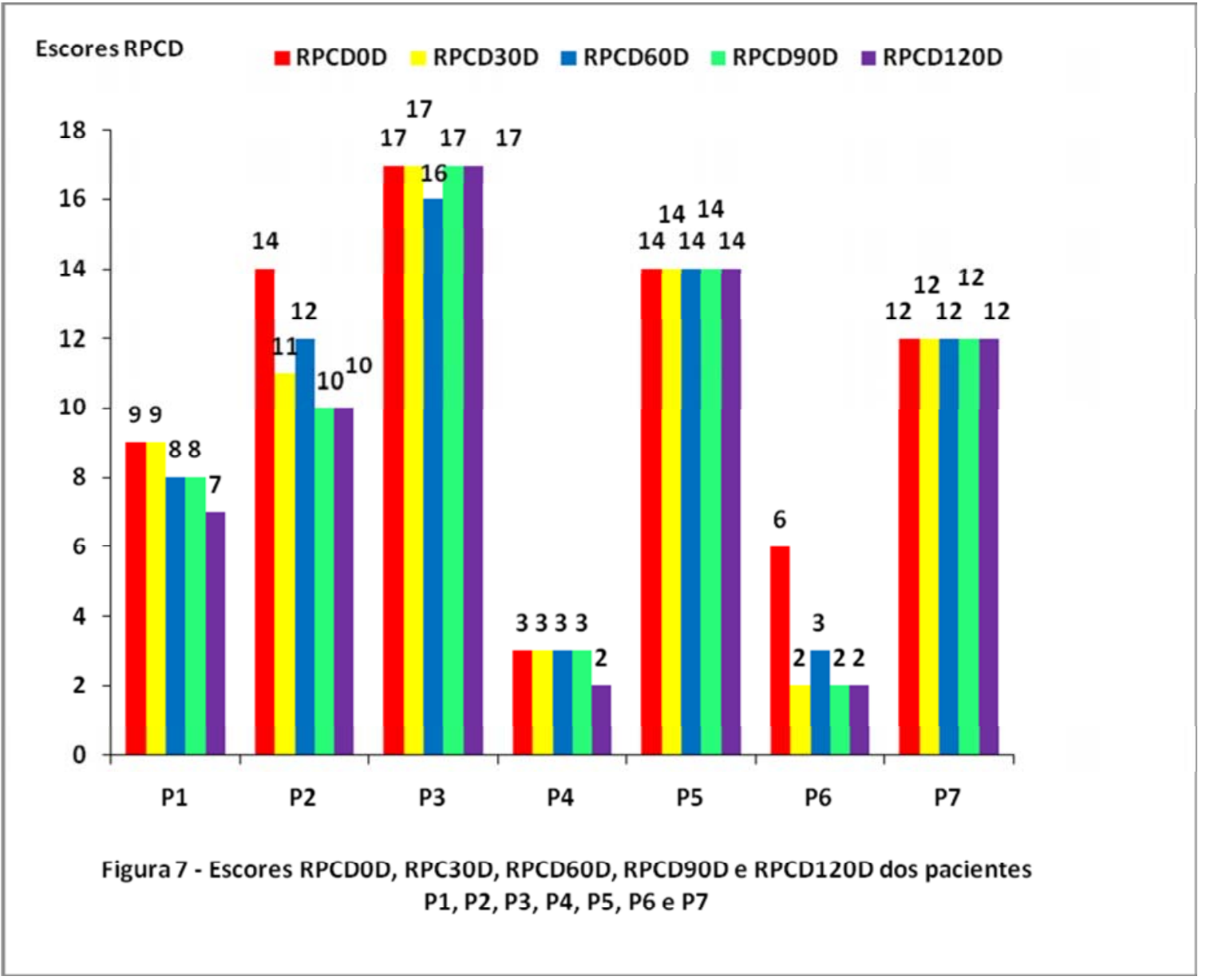

A Figura 8 regista a melhora porcentual dos pacientes entre a intervenção psicológica inicial e final levando-se em consideração as RPCD. Houve melhora para 4 pacientes, P2, P3, P4 e P6.

O paciente P3 não apresentou melhora porcentual, pois permaneceu classificado em alerta em RPCD em todos os momentos; os pacientes P5 e P7 não apresentaram melhora porcentual, pois permaneceram classificados normais em todos os momentos (Tabela $7 \mathrm{e}$ Figura 8). 


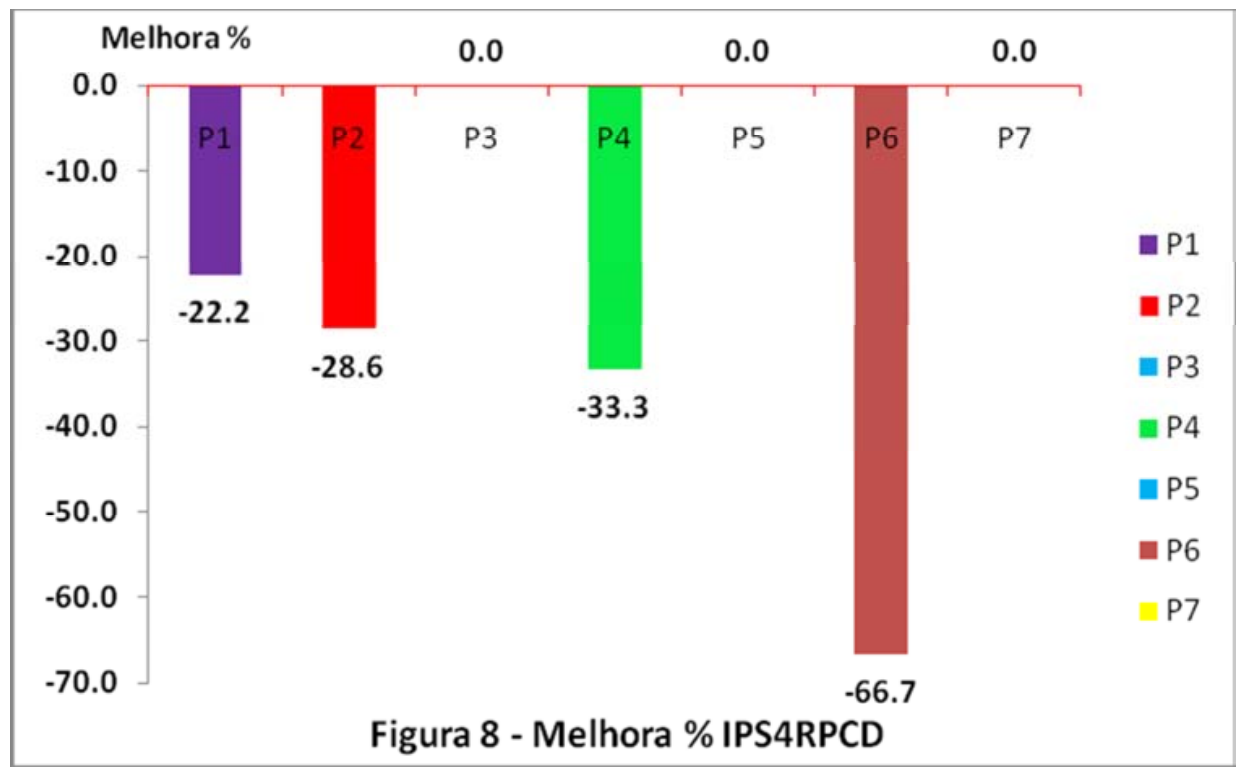

\section{REAÇÕES PSICOFISIOLÓGICAS (RPF)}

Quando se analisa o escore do estresse infantil levando em consideração a variável: reações psicolfisiológicas (RPF), observa-se que somente para o paciente P2 houve registro de melhora final em relação ao início. O paciente P3 não apresentou melhora porcentual, pois permaneceu classificado alerta em RPF em todos os momentos. Os demais pacientes P1, P4, P5, P6 e P7 foram classificados como normais, não apresentando estresse infantil em nenhum momento para as RPF (Tabela 6 e Figura 9).

Tabela 6 - Apresentação dos resultados qualitativos obtidos com o escore padronizado da ESI, caracterizados por fases, sendo estas: normal, alerta, resistência e stress, segundo as reações psicofisiológicas (RPF)

\begin{tabular}{l|l|l|l|l|l}
\hline Paciente & RPF0D & RPF30D & RPF60D & RPF90 & RPF120D \\
\hline $\mathbf{P 1}$ & NORMAL & NORMAL & NORMAL & NORMAL & NORMAL \\
\hline $\mathbf{P 2}$ & RESISTENCIA & ALERTA & ALERTA & ALERTA & NORMAL \\
\hline $\mathbf{P 3}$ & ALERTA & ALERTA & ALERTA & ALERTA & ALERTA \\
\hline $\mathbf{P 4}$ & NORMAL & NORMAL & NORMAL & NORMAL & NORMAL \\
\hline $\mathbf{P 5}$ & NORMAL & NORMAL & NORMAL & NORMAL & NORMAL \\
\hline $\mathbf{P 6}$ & NORMAL & NORMAL & NORMAL & NORMAL & NORMAL \\
\hline $\mathbf{P 7}$ & NORMAL & NORMAL & NORMAL & NORMAL & NORMAL \\
\hline
\end{tabular}




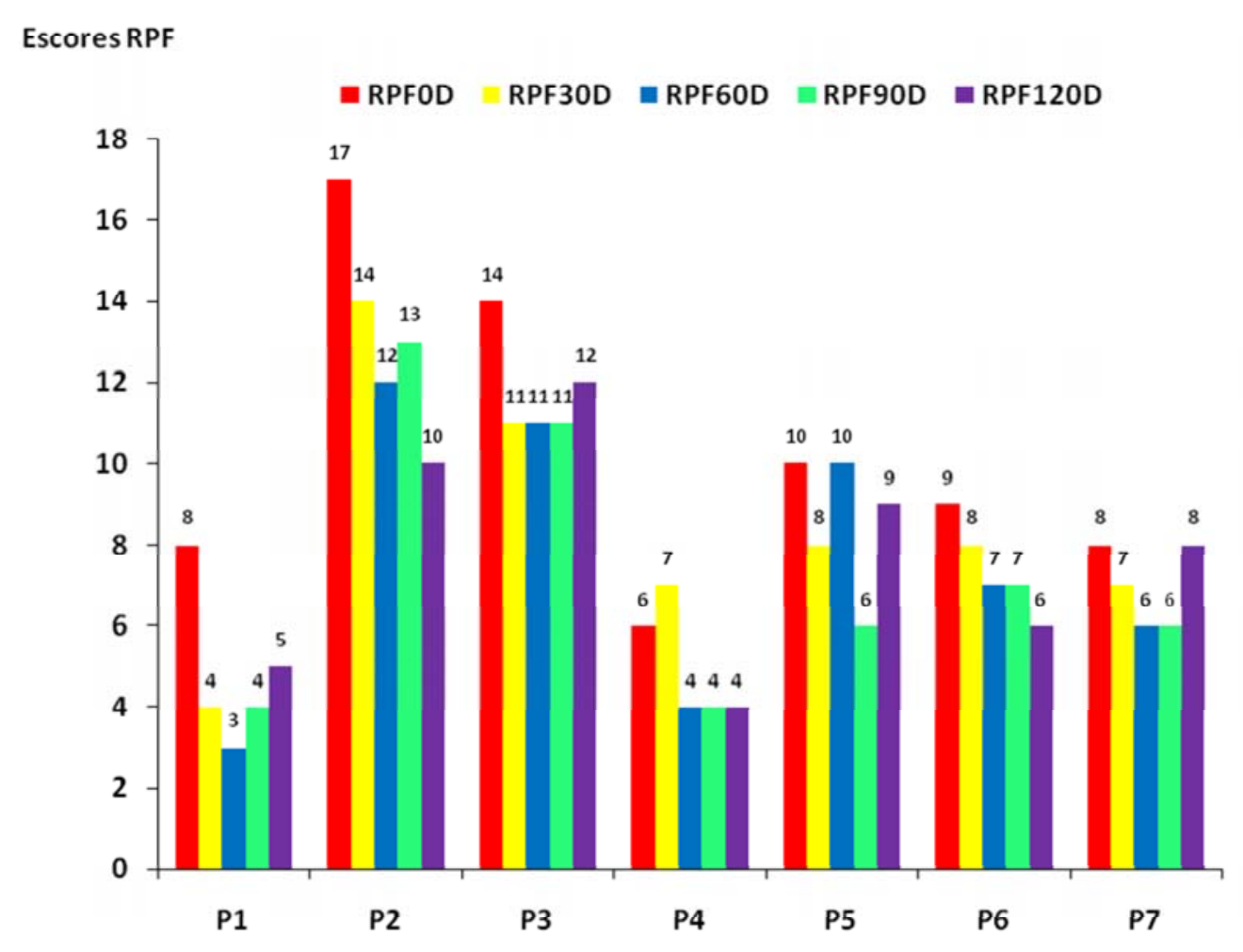

Figura 9 - Escores RPF0D, RPF30D, RPF60D, RPF90D e RPF120D dos pacientes P1, P2, P3, P4, P5, P6 e P7

As RPF tiveram o percentual de escores avaliados e registrados na Figura 10. Houve melhora para seis pacientes, P1, P2, P3, P4, P5 e P6.

Não foi registrado melhora para o paciente P7, no entanto foi classificado como normal em todos os tempos. 


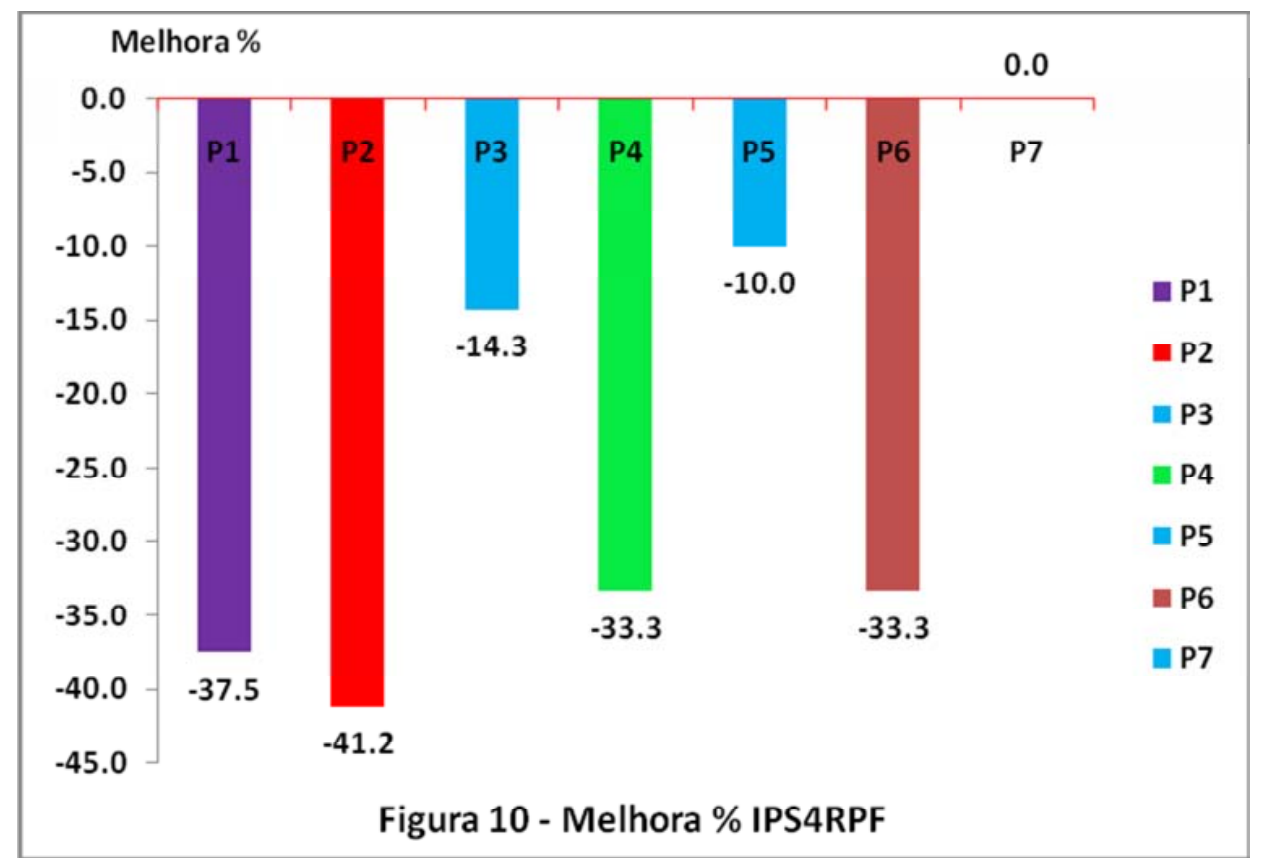

ESCORES DA ESCALA ESI SEGUNDO AS REAÇÕES: RF, RP, RPCD E RPF NOS MOMENTOS INICIAL (T0) E FINAL (T120)

Em relação ao momento inicial, antes da intervenção psicológica, o paciente P4, apresentou-se em fase normal em todos os aspectos avaliados. P6 apresentou-se em fase de alerta em RP e em fase normal nos outros aspectos avaliados. Os pacientes P5 e P7 apresentaram-se em fase de resistência em RP, de alerta em RPCD e normal nos outros aspectos avaliados. P1 apresentou-se em fase de alerta em RF, RP e RPCD, sendo normal em RPF. P3 apresentou-se em fase de alerta em RP e RPF, resistência em RPCD e normal em RF. O paciente P2 foi o que apresentou o maior nível de estresse, com fase de Quaseexaustão em RP, alerta em RPCD e resistência em RPF e RF (Tabela 7). 
Tabela 7- Resumo dos escores da Escala de Stress Infantil ( ESI), caracterizados por fases: normal, alerta, resistência e quase-exaustão, no momento inicial (T0)

\begin{tabular}{l|l|l|l|l}
\hline Paciente & RF & RP & RPCD & RPF \\
\hline P1 & Alerta (11) & Alerta (20) & Alerta (9) & Normal (8) \\
\hline P2 & Resistência (17) & Quase-exaustão (31) & Alerta (14) & Resistência (17) \\
\hline P3 & Normal (9) & Alerta (17) & Resistência (17) & Alerta (14) \\
\hline P4 & Normal (7) & Normal (8) & Normal (3) & Normal (6) \\
\hline P5 & Normal (7) & Resistência (25) & Alerta (14) & Normal (10) \\
\hline P6 & Normal (8) & Alerta (16) & Normal (6) & Normal (9) \\
\hline P7 & Normal (7) & Resistência (24) & Alerta (12) & Normal (8) \\
\hline Mediana & Normal (8) & Alerta (20) & Alerta (12) & Normal (9) \\
\hline
\end{tabular}

$\mathrm{RF}=$ reações físicas; $\mathrm{RP}=$ reaçãoes pscológicas; $\mathrm{RPCD}=$ reações físicas com componente depressivo e $\mathrm{RPF}=$ reações psico-fisiológicas

Em relação ao momento final, T120, depois da intervenção psicológica, o paciente P4, manteve-se sem estresse, apresentando-se em fase normal em todos os aspectos avaliados.

P6 que inicialmente (T0) estava em alerta em RP, melhorou após as intervenções apresentando-se em fase normal em todos os aspectos avaliados no final (T120).

Os pacientes P5 e P7 mantiveram no final (T120) os níveis que apresentaram no início (T0), fase de resistência em RP, de alerta em RPCD e normal nos outros aspectos avaliados.

P1 melhorou após as intervenções apresentando-se em T120 fase normal em RPCD que inicialmente (T0) estava em alerta; manteve os outros aspectos avaliados em fase de alerta em RF e RP e normal em RPF.

P3 melhorou após as intervenções apresentando-se em T120 fase normal em RP que inicialmente (T0) estava em alerta; manteve os outros aspectos avaliados em fase de alerta em RF, resistência em RPCD e normal em RF.

O paciente P2 melhorou após as intervenções saindo do maior nível de estresse em T0 onde estava em fase de Quase-exaustão em RP e passou para resistência em T120; alerta em RF e RPCD, e normal em RPF (Tabela 8). 
Tabela 8 - Resumo dos escores da Escala de Stress Infantil ( ESI), caracterizados por fases: normal, alerta, resistência e quase-exaustão, no momento final (T120)

\begin{tabular}{l|l|l|l|l}
\hline Paciente & RF & RP & RPCD & RPF \\
\hline P1 & Alerta (13) & Alerta (21) & Normal (7) & Normal (5) \\
\hline P2 & Alerta (10) & Resistência (26) & Alerta (10) & Normal (10) \\
\hline P3 & Normal (8) & Normal (13) & Resistência (17) & Alerta (12) \\
\hline P4 & Normal (2) & Normal (7) & Normal (2) & Normal (4) \\
\hline P5 & Normal (7) & Resistência (25) & Alerta (14) & Normal (9) \\
\hline P6 & Normal (5) & Normal (11) & Normal (2) & Normal (6) \\
\hline P7 & Normal (7) & Resistência (26) & Alerta (12) & Normal (8) \\
\hline Mediana & Normal (7) & Alerta (21) & Alerta (10) & Normal (8) \\
\hline
\end{tabular}

$\mathrm{RF}=$ reações físicas; $\mathrm{RP}=$ reaçãoes pscológicas; $\mathrm{RPCD}=$ reações físicas com componente depressivo e $\mathrm{RPF}=$ reações psico-fisiológicas

\section{3 CORRELAÇÃO ENTRE IDADE, SEXO, ESCORES CDI E ESI}

$\mathrm{Na}$ Tabela 9 encontram-se as correlações positivas fortes, significantes $(\mathrm{p}<0,05)$, entre reações físicas inicial (T0), final (T120), CDI inicial e CDI final, ou seja, conforme maiores valores de depressão, maiores sintomas físicos.

Nas demais variáveis, idade, sexo e escores de RF (T30,T60,T90), RP (todos os momentos), RPCD (todos os momentos), RPF (todos os momentos) e CDI (T30,T60,T90), não foram observadas correlações estatísticas significantes.

Tabela 9 - Correlação entre escores RF0D, RF120D, CDI0D e CDI120D

\begin{tabular}{c|c|c|c}
\hline & Coeficiente $\mathbf{r}_{\mathbf{S}} ; \mathbf{p}$ & CDI0D & CDI120D \\
\hline \multirow{2}{*}{ RF0D } & $\mathrm{r}_{\text {Spearmann }}$ & $0,852^{*}$ & $0,841^{*}$ \\
& $\mathrm{p}$ & 0,015 & 0,018 \\
\hline \multirow{2}{*}{ RF120D } & $\mathrm{r}_{\text {Spearmann }}$ & $0,847^{*}$ & $0,882^{* *}$ \\
& $\mathrm{p}$ & 0,016 & 0,009 \\
\hline
\end{tabular}

*Significante 


\section{CONCLUSÕES}

Quando se analisa os escores CDI ao final do período das intervenções observou-se uma melhora no estado geral dos sintomas de depressão dos participantes (escores finais aos 120 dias inferiores a 17) comprovando a eficácia da intervenção psicoterapêutica de base analítica na melhora dos sintomas em crianças e adolescentes portadores de neoplasias onco-hematológicos.

Os dados dos inventários de estresse infantil são semelhantes aos de depressão apontando para a eficácia da abordagem psicoterapêutica.

As variáveis da fase reações físicas (ESI) estão associadas aos índices de presença e gravidade do transtorno depressivo (CDI) nos momentos inicial e final deste estudo.

Diante deste estudo evidencia-se que o papel da psicologia torna-se de primordial importância, no sentido de favorecer uma real compreensão, dos mecanismos egóicos, o estresse, a depressão nesse processo de adoecer para alcançar uma melhor qualidade de vida.

Este trabalho, não teve a pretensão de esgotar o assunto, mas sim contribuir para uma reflexão acerca dos aspsctos emocionais da criança e adolescente com câncer, e as possibilidades da intervenção picoterapêutica de base analítica na onco-hematologia pediátrica, a fim de sensibilizar os profissionais de saúde para necessidade da presença deste profissional nas equipes multidisciplinares, como mais uma peça fundamental no tratamento de crianças e adolescentes com câncer proporcionando um atendiamento humanizado e com qualidade de vida. 


\section{REFERÊNCIAS}

1-ABERASTURY. A percepção na morte da criança e outros escritos. Porto Alegre: Artes Medicas, 1984.

2-ANGERAMI - CAMON, V. A., org. A psicologia no hospital. São Paulo: Traço, 1987.

3- BERTAZZI, R. G. M.; PANDINI, A. L. R. Reações psicológicas evocadas em crianças com câncer submetidas a radioterapia. Rev: Psicol. Hospi., São Paulo, v.2. n.2, p. 21-27, jul./dez. 1992.

4- BOWLBY, J. Perda: tristeza e depressão. São Paulo: Martins Fontes, 1985.

5- BRASIL. Ministério da Saúde. Instituto Nacional do Câncer - INCA. Estimativa/2008: Incidência de Câncer no Brasil. Rio de Janeiro, 2007.

6- BRUN, D. A crianças dada por morta: riscos psíquicos da cura. São Paulo: Casa do psicólogo, 1996.

7- CALLEGARI-JACQUES, S. M. Bioestatística: princípios e aplicações. Porto Alegre: Artmed, 2003. 255p.

8- CAMARGO, B.; LOPES, L. F. Noções Fundamentais para a Pediatria. São Paulo: Leniar, 2000.

9- CAMARGO, M.C.; MARX, A.G. Reabilitação no câncer de mama. São Paulo: Roca; 2000.

10- CARDOSO, F.T. Cancer infantil: aspectos emocionais e atuação do psicólogo. Rev: SBPH., Rio de Janeiro, v.10 n.1. 2007.

11- CARValho, M. M. (1998a). Abrindo um espaço para a psiconcologia. In S. Bettarello (Org.), Perspectivas psicodinâmicas em psiquiatria. São Paulo: Lemos.

12- CARVAlhO, M. M. (1998b). Psico-oncologia no Brasil: Resgatando o viver. São Paulo: Summus.

13- CARVALHO, M.M. Imunologia, estresse, câncer e o programa Simonton de auto ajuda. Boletim da Academia Paulista de Psicologia, 10 (1), 27-30,2000.

14- CHIATTONE, H.B.C. A criança e a hospitalização. São Paulo: Pioneira, 2003.

15- DAVIS, M et AL. Manual de Relaxamento e Redução do Estresse. São Paulo: Summus, 1996. 
16- DEITOS, T.F.H.; GASPARY, J.F.P. Mito de Ulisses: estresse, câncer e imunidade. Santa Maria: Kaza do Zé, 1997.

17- EIZIRIK, C.L; AGUIAR, RW; SCHESTATSKY, S.S. e colaboradores.

Psicoterapia de orientação analítica. Porto Alegre: Artmed, 2005.

18- FIORINI, H. Teoria e Técnicas Psiquiátricas. Rio de Janeiro: Francisco Alves, 1982.

19- FREUD, S. (1893 - 1895). Edição Standart Brasileira das Obras Psicológicas Completas. Rio de Janeiro: Imago, 1974. v.2.

20- GOUVEIA, V.V., et AL. Inventario de depressão infantil - CDI: estudo de adaptação com escolares de João Pessoa. Jornal Brasileiro de Psiquiatria, Rio de Janeiro, v. 44, n. 7, p. 345-349, 1995

21- HULLEY, S.B.; CUMMINHGS, S.R.; BROWNER, W.S.; GRADY, D.; HEARST, N.; NEWMAN, T.B. Delineado pesquisa clinica: uma abordagem epidemiológica. Porto Alegre: Artmed; 2003

22- KOVÁCS, M.J. Morte e desenvolvimento humano. São Paulo: Casa do psicólogo, 1992.

23- KLEIN, M. Amor, culpa e reparação. Rio de Janeiro: Imago, 1996.

24- KLEIN, M. A psicanálise de crianças. Rio de Janeiro: Imago, 1997.

25- KLEIN, M.; HEIMANN, P.; MONEY-KYRLE, R.E. (Org). Novas tendências na psicanálise. Rio de Janeiro: Zahaar, 1969.

26- KUBELER-ROSS, E. Sobre a morte e o morrer. $8^{\text {a }}$ ed. São Paulo: Martins Fontes, 1988.

27- LAPLANCHE, J; PONTALIS, J.B. Vocabulário da psicanálise. São Paulo: Martins Fontes, 1992.

28- LAZARUS, R.S. Psychological stress and the coping process. New York: McGrawHill, 1996.

29- LESHAN, L. Brigando pela vida: Aspectos emocionais do câncer. São Paulo: Summus, 1994.

30- MELlO filHO, J. Psicossomática Hoje. Porto Alegre: Artes Médias Sul, 1992.

31- MENOSSI, M.J.; LIMA, R.A.G. A Problemática do sofrimento: Percepçap do adolescente com câncer. Rev. Esc. Enf. USP, v. 34, n.1, mar.2000.

32- NEDER, M. O psicólogo no hospital. Rev: Psicol. Hospi., v.1, p.6-15, 1991. 
33- PEREIRA, F.D. Experiência da criança com câncer hospitalizada em ambiente de isolamento protetor. Rev. Pediatria atual: Porto Alegre, v.14 nº 8, agosto 2001.

34- RODRIGUES, K.E.;CAMARGO,B. Diagnostico precoce do câncer infantil: Responsabilidade de todos. Rev. da Associação Médica Brasileira. São Paulo, v.49, n.1, 2003.

35- ROMANO, B.W. Princípios para a pratica da Psicologia clinica em hospitais. São Paulo: Casa do Psicólogo, 1999.

36-RONA, E.\& VARGAS, L. El Impacto Psicológico del Câncer en el niño y adolescente. Rev. Chilena de pediatria. V.65, n. 1, 1994.

37- SALOMÃO, J., dir. Três ensaios sobre a teoria da sexualidade. Rio de Janeiro: Imago, 1973. (Pequena coleção das obras de Freud, v.2)

38- SIMONETTI, A. Manual de psicologia hospitalar: O mapa da doença. São Paulo: Casa do Psicólogo, 2004.

39- SIMONTON, O.C.; \& CREIGHTON, J.L. Com a vida de novo: Uma abordagem de auto-ajuda para pacientes com câncer. Sao Paulo: Summus, 1987.

40- VALLE, E. R. M.; FRANÇOSO, L. P. C. Psico-oncologia pedriática: vivências de crianças com câncer. Ribeirão Preto: Scala, 1999.

41- VALLE, E.R.M. (org). Psico-oncologia Pediatrica. Sao Paulo: Casa do Psicologo, 2001.

42- VANCE, Y. H.; EISER, C. The school experience of the child with câncer. Child:

Carie, Health \& Development, 28(1):5-19,2002. 


\title{
APÊNDICE A TERMO DE CONSENTIMENTO LIVRE E ESCLARECIDO
}

\author{
Título da Pesquisa: "AVALIAÇÃO DA INTERVENÇÃO PSICOTERAPÊUTICA DE \\ MODELO ANALİTICO EM CRIANÇAS E ADOLESCENTES COM DOENÇAS \\ ONCO-HEMATOLOGICA"”.
}

Nome do (a) Pesquisador (a): Silvana de Oliveira Cantu

Nome do (a) Orientador (a): Profa. Dra. Elenice Deffune

O seu filho (a) está sendo convidado a participar da pesquisa sobre"Correlação entre a Intervenção Psicológica em Pacientes com Doenças Onco-Hematológica e qualidade de Vida.

A participação do seu filho (a) não é obrigatória. O seu filho (a) tem liberdade de recusar a participar e ainda se recusar a continuar a participando em qualquer fase da pesquisa, sem qualquer prejuízo para ele, comunicando ao pesquisador o desligamento da pesquisa. Sempre que quiser poderá pedir maiores informações sobre a pesquisa através do telefone do (a) pesquisador do projeto e, se necessário através do Comitê de Ética em Pesquisa.

Os objetivos desse estudo é analisar a contribuição do atendimento psicológico no tratamento de pacientes portadores de Leucemia Infanto Juvenil.

Analisar o índice de estresse, ansiedade, depressão e qualidade de vida.

Comparar a sobrevida de pacientes com acompanhamento psicológico com aqueles não seguidos pelo atendimento psicológico.

A participação do seu filho (a) consistirá em ser submetido a atendimento psicológico semanal, no Hemocentro de Marilia. No decorrer dos atendimentos, serão aplicados questionários com questões relacionadas aos aspectos da depressão, ansiedade e qualidade de vida.

Os procedimentos utilizados nesta pesquisa obedecem aos Critérios da Ética na Pesquisa com Seres Humanos conforme resolução n. 196/96 do Conselho Nacional de Saúde-Brasília-DF.

Todas as informações coletadas neste estudo são estritamente confidências. Somente o (a) pesquisador e o orientador (a) terão o conhecimento dos dados.

Ao participar desta pesquisa seu filho (a) não terá nenhum beneficio direto. Entretanto esperamos que este estudo traga informações importantes sobre a importância do tratamento psicológico aos pacientes portadores de doenças oncohematológicas.

O seu filho não terá nenhum tipo de despesa para participar desta pesquisa, bem como nada será pago pela participação.

Após estes esclarecimentos, solicitamos o seu consentimento de forma livre para permitir a participação de seu filho (a) nesta pesquisa. Portanto, preencha os itens que seguem:

$\mathrm{Eu}$,

RG autorizo a participação do meu filho (a) , após a leitura e compreensão destas informações, que está sob minha responsabilidade, e voluntária, e que ele (a) pode sair a qualquer momento do estudo, sem prejuízo algum. 
Confiro que recebi cópia deste termo de consentimento, e autorizo a execução do trabalho de pesquisa e a divulgação dos dados obtidos neste estudo.

Marília

Nome do Voluntario:

Assinatura do Responsável:

Assinatura do Pesquisador:

Assinatura do Orientador

Telefone de Contato do Pesquisador (a): Silvana de Oliveira Cantu - Hemocentro de Marília/ 1434021843

(14) $3402-1840$

Cel.: (14) 9786- 1477

Telefone de Contato do Orientador: Dra. Elenice Deffune - Hemocentro de Botucatu (14) 3811-6041 - ramal 218 
ANEXOS

\section{ANEXO A - INVENTÁRIO DE DEPRESSÃO INFANTIL - CDI}

INDIVÍDUO:

Itens do Inventário de Depressão Infantil (CDI)

Golfeto, J.H.; Veiga, M.H.; Souza, L.; Barbeira, C. Rev. Psiq. Clín. 29 (2):66

\begin{tabular}{|c|c|c|c|c|c|c|c|c|}
\hline & & ITENS & Escore & 0 & 30 & 60 & 90 & 120 \\
\hline 1 & 0 & Eu fico triste de vez em quando & 0 & & & & & \\
\hline & 1 & Eu fico triste muitas vezes & 1 & & & & & \\
\hline & 2 & Eu estou sempre triste & 2 & & & & & \\
\hline 2 & 0 & Para mim, tudo se resolverá bem & 0 & & & & & \\
\hline & 1 & Eu não tenho certeza se as coisas darão certo para mim & 1 & & & & & \\
\hline & 2 & Nada vai dar certo para mim & 2 & & & & & \\
\hline 3 & 0 & Eu faço bem a maioria das coisas & 0 & & & & & \\
\hline & 1 & Eu faço errado a maioria das coisas & 1 & & & & & \\
\hline & 2 & Eu faço tudo errado & 2 & & & & & \\
\hline 4 & 0 & Eu me divirto com muitas coisas & 0 & & & & & \\
\hline & 1 & Eu me divirto com algumas coisas & 1 & & & & & \\
\hline & 2 & Nada é divertido para mim & 2 & & & & & \\
\hline 5 & 0 & Eu sou mau (má) de vez em quando & 0 & & & & & \\
\hline & 1 & Eu sou mau (má) com freqüência & 1 & & & & & \\
\hline & 2 & Eu sou sempre mau (má) & 2 & & & & & \\
\hline 6 & 0 & $\begin{array}{l}\text { De vez em quando, eu penso que coisas ruins vão me } \\
\text { acontecer }\end{array}$ & 0 & & & & & \\
\hline & 1 & Eu temo que coisas ruins aconteçam & 1 & & & & & \\
\hline & 2 & Eu tenho certeza de que coisas terríveis me acontecerão & 2 & & & & & \\
\hline 7 & 0 & Eu gosto de mim mesmo & 0 & & & & & \\
\hline & 1 & Eu não gosto de mim & 1 & & & & & \\
\hline & 2 & Eu me odeio & 2 & & & & & \\
\hline 8 & 0 & $\begin{array}{l}\text { Normalmente, eu não me sinto culpado pelas coisas } \\
\text { ruins que acontecem }\end{array}$ & 0 & & & & & \\
\hline & 1 & Muitas coisas ruins que acontecem são minha culpa & 1 & & & & & \\
\hline & 2 & Tudo de mau que acontece é por minha culpa & 2 & & & & & \\
\hline 9 & 0 & Eu não penso em me matar & 0 & & & & & \\
\hline & 1 & Eu penso em me matar, mas não faria & 1 & & & & & \\
\hline & 2 & Eu quero me matar & 2 & & & & & \\
\hline 10 & 0 & Eu sinto vontade de chorar de vez em quando & 0 & & & & & \\
\hline & 1 & Eu sinto vontade de chorar freqüentemente & 1 & & & & & \\
\hline & 2 & Eu sinto vontade de chorar diariamente & 2 & & & & & \\
\hline
\end{tabular}




\begin{tabular}{|c|c|c|c|c|c|c|c|c|}
\hline & & ITENS & Escore & 0 & 30 & 60 & 90 & 120 \\
\hline \multirow[t]{3}{*}{11} & 0 & Eu me sinto preocupado de vez em quando & 0 & & & & & \\
\hline & 1 & Eu me sinto preocupado freqüentemente & 1 & & & & & \\
\hline & 2 & Eu me sinto sempre preocupado & 2 & & & & & \\
\hline \multirow[t]{3}{*}{12} & 0 & Eu gosto de estar com pessoas & 0 & & & & & \\
\hline & 1 & Freqüentemente, eu não gosto de estar com pessoas & 1 & & & & & \\
\hline & 2 & Eu não gosto de estar com pessoas & 2 & & & & & \\
\hline \multirow[t]{3}{*}{13} & 0 & Eu tenho boa aparência & 0 & & & & & \\
\hline & 1 & Minha aparência tem alguns aspectos negativos & 1 & & & & & \\
\hline & 2 & Eu sou feio & 2 & & & & & \\
\hline \multirow[t]{3}{*}{14} & 0 & Eu durmo bem à noite & 0 & & & & & \\
\hline & 1 & Eu tenho dificuldades para dormir algumas noites & 1 & & & & & \\
\hline & 2 & Eu tenho sempre dificuldades para dormir à noite & 2 & & & & & \\
\hline \multirow[t]{3}{*}{15} & 0 & Eu me canso de vez em quando & 0 & & & & & \\
\hline & 1 & Eu me canso freqüentemente & 1 & & & & & \\
\hline & 2 & Eu estou sempre cansado & 2 & & & & & \\
\hline \multirow[t]{3}{*}{16} & 0 & Eu não me sinto sozinho & 0 & & & & & \\
\hline & 1 & Eu me sinto sozinho muitas vezes & 1 & & & & & \\
\hline & 2 & Eu sempre me sinto sozinho & 2 & & & & & \\
\hline \multirow[t]{3}{*}{17} & 0 & Eu me divirto na escola freqüentemente & 0 & & & & & \\
\hline & 1 & Eu me divirto na escola de vez em quando & 1 & & & & & \\
\hline & 2 & Eu nunca me divirto na escola & 2 & & & & & \\
\hline \multirow[t]{3}{*}{18} & 0 & Sou tão bom quanto outras crianças & 0 & & & & & \\
\hline & 1 & $\begin{array}{l}\text { Se eu quiser, posso ser tão bom quanto outras } \\
\text { crianças }\end{array}$ & 1 & & & & & \\
\hline & 2 & Não posso ser tão bom quanto outras crianças & 2 & & & & & \\
\hline \multirow[t]{3}{*}{19} & 0 & Eu tenho certeza de que sou amado por alguém & 0 & & & & & \\
\hline & 1 & Eu não tenho certeza se alguém me ama & 1 & & & & & \\
\hline & 2 & Ninguém gosta de mim realmente & 2 & & & & & \\
\hline \multirow[t]{3}{*}{20} & 0 & Eu sempre faço o que me mandam & 0 & & & & & \\
\hline & 1 & Eu não faço o que me mandam com freqüência & 1 & & & & & \\
\hline & 2 & Eu nunca faço o que me mandam & 2 & & & & & \\
\hline
\end{tabular}




\title{
Escala de Stress Infantil — ESI
}

\author{
Caderno de Aplicação
}

Marilda Emmanuel Novaes Lipp / Maria Diva Monteiro Lucarelli

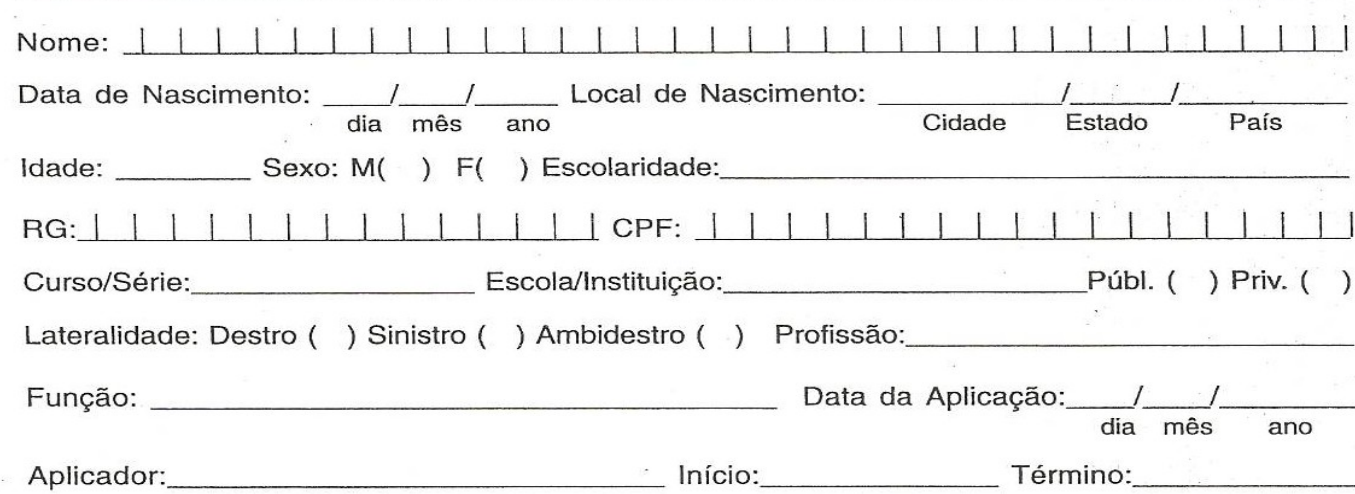

Autorizo uso sigiloso em pesquisa:

assinatura

INSTRUÇÓES: Você encontrará nas questôes abaixo coisas que as crianças podem ter ou sentir. Você deverá mostrar o quanto acontece com você o que está descrito em cada questão, pintando os desenhos assim:

- Sẹ NUNCA acontece, deixe em branco $\oplus$

- Se acontece UM POUCO, pinte UMA PARTE $\oplus$

- Se acontece ÀS VEZES, pinte DUAS PARTES $\theta$

- Se acontece QUASE SEMPRE, pinte TRES PARTES

- Se SEMPRE acontece, pinte TODAS AS PARTES

1. Estou o tempo todo me mexendo e fazendo coisas diferentes.

2. Demoro para conseguir usar o banheiro.

3. Tenho dificuldade de prestar atenção. $\bigoplus$

4. Eu me sinto assustado na hora de dormir. $\bigoplus$

5. Fico preocupado com coisas ruins que podem acontecer. $\oplus$

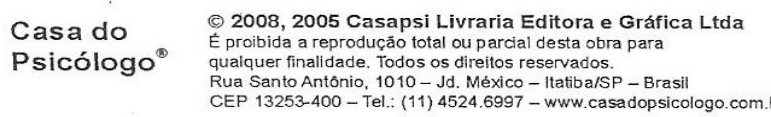


- Se NUNCA acontece, deixe em branco $\oplus$

- Se acontece UM POUCO, pinte UMA PARTE

- Se acontece ÀS VEZES, pinte DUAS PARTES

- Se acontece QUASE SEMPRE, pinte TRÊS PARTES

- Se SEMPRE acontece, pinte TODAS AS PARTES

6. Raspo um dente no outro fazendo barulho. $\oplus$

7. Fico nervoso com tudo. $\oplus$

8. Sinto aflição por dentro.

9. Tenho ficado tímido, envergonhado.

10. Eu me sinto triste

11. Minhas mãos ficam suadas.

12. Tenho diarréia.

13. Sinto que tenho pouca energia para fazer as coisas.

14. De repente, passei a não gostar mais de estudar. $\bigoplus$

15. Tenho vontade de chorar.

16. Quando fico nervoso, gaguejo.

17. Quando fico nervoso, fico com yontade de vomitar.

18. Meu coração bate depressa, mesmo quando não corro ou pulo.

19. Minhas pernas e braços doem.

20. Tenho vontade de bater nos colegas, sem razão. 
- Se NUNCA acontece, deixe em branco $\bigoplus$

- Se acontece UM POUCO, pinte UMA PARTE

- Se acontece Às VEZES, pinte DUAS PARTES

- Se acontece QUASE SEMPRE, pinte TRÊS PARTES

- Se SEMPRE acontece, pinte TODAS AS PARTES

21. Quando fico nervoso durante o dia, molho a cama à noite.

22. Tenho vontade de sumir da vida.

23. Tenho dificuldade para respirar.

24. Tenho dor de barriga. $\bigoplus$

25. Penso qủe sou feio, ruim, que não consigo aprender as coisas.

26. Tenho medo.

27. Ténho comido demais.

28. Náo tenho vontade de fazer as coisas.

29. Tenho andado muito esquecido. $\oplus$

30. Tenho dificuldade de dormir.

31. Não tenho fome.

32. Brigo com minha família em casa.

33. Estou sempre resfriado, com dor de garganta.

34. Sinto muito sono.

35. Não tenho vontade nenhuma de me arrumar. 


\section{ANEXO C- AVALIAÇÃO DOS RESULTADOS ESI}

\section{Avaliação dos Resultados}

A experiência clínica, aliada a análise estatística, mostra que em áreas muito novas como a do estudo do stress infantil, o profissional necessita de medidas mais quantitativas para poder ter maior confiança na análise dos dados e do quadro sintomatológico detectado.

Desse modo, os critérios abaixo são recomendados para diagnóstico do stress infantil, em cada uma de suas fases.

\section{Fase de Alerta}

Considerada como uma fase transitória do stress, que não deve-ser vista como envolvendo stress emocional permanente ou grave, mas representa uma reação do organismo a algo presente, no momento, que representa um desafio para a criança.

\section{Critérios:}

1. Nota igual ou maior que 10 pontos obtida no fator "reações físicas" (itens $2,6,12,15,17,19,21,24 \mathrm{e}$ 34) ou;

2. Nota igual ou maior que 15 pontos obtida no fator "reações psicológicas" (itens $4,5,7,8,10,11,26,30$ e 31) ou;

3. Nota igual ou maior que 9 pontos obtida no fator "reações psicológicas com componente depressivo" (itens $13,14,20,22,25,28,29,32$ e 35 ) ou;

4. Nota igual ou maior que 11 pontos obtida no fator "reações psicofisiológicas" (itens $1,3,9,16,18,23$, 27 e 33) ou,

5. Nota total da escala entre 39,60 e 59,50 pontos.

\section{Fase de Resistência}

Caracteriza-se por um excesso de fontes de stress na vida da criança, que a estão levando a utilizar muita energia para seu enfrentamento. $O$ organismo entra nesta fase quando o estressor permanece atuante por muito tempo.

\section{Critérios:}

1. Nota igual ou maior que 16 pontos obtida no fator "reações físicas" (itens $2,6,12,15,17,19,21,24 \mathrm{e}$ 34) ou; 
4. Nota igual ou maior que 16 pontos obtida no fator "reações psicofisiológicas" (itens 1, 3, 9, 16, 18, 23, 27 e 33) ou,

5. Nota total da escala acima de 59,50 até 79,40 pontos.

\section{Fase de Quase-exaustão}

Caracteriza-se como uma fase muito grave do stress, na qual a criança não mais consegue resistir aos estressores presentes em sua vida e começa a adoecer física ou psicológicamente.

\section{Critérios:}

1. Nota igual ou maior que 22 pontos obtida no fator "reações físicas" (itens 2, 6, 12, 15, 17, 19, 21, 24 e 34) ou;

2. Nota igual ou maior que 29 pontos obtida no fator "reações psicológicas" (itens 4, 5, 7, 8, 10, 11, 26, 30 e 31) ou;

3. Nota igual ou maiō que 21 pontos obtida no fator "reações psicológicas com componente depressivo" (itens $13,14,20,22,25,28,29,32$ e 35 ) ou

4. Nota igual ou maior que 21 pontos obtida no fator "reações psicofisiológicas" (itens $1,3,9,16,18,23$, 27 e 33) ou;

5. Nota total da escala acima de 79,40 pontos até 99,30 pontos ou,

6. Aparecem círculos completamente cheios (pintados) em 7 ou mais itens da escala total.

\section{- $\quad$ Fase de Exaustão}

Caracteriza-se como a fase mais grave do stress, na qual a criança adoece física ou psicologicamente.

\section{Critério:}

1. Nota total da escala acima de 99,30 pontos, independente da pontuação nos demais critérios referentes aos diversos fatores do stress. 


\section{Escala de Stress Infantil - ESI}

\section{Protocolo de Apuração}

Marilda Emmanuel Novaes Lipp / Maria Diva Monteiro Lucarelli

Nome:

Sexo: Idade:

Escolaridade

Escola:

\begin{tabular}{|c|c|c|c|c|c|c|c|}
\hline \multicolumn{2}{|c|}{$\begin{array}{c}\text { Reaçóes } \\
\text { Físicas }\end{array}$} & \multicolumn{2}{c|}{$\begin{array}{c}\text { Reaçóes } \\
\text { Psicológicas }\end{array}$} & \multicolumn{2}{c|}{$\begin{array}{c}\text { Reaçóes } \\
\text { Psicológicas cl } \\
\text { componente depressivo }\end{array}$} & \multicolumn{2}{c|}{$\begin{array}{c}\text { Reaçóes } \\
\text { Psicofisiológicas }\end{array}$} \\
\hline Itens & Pontuaçáo & Itens & Pontuação & Itens & Pontuaçáo & Itens & Pontuaçáo \\
\hline 2. & & 4 & & 13 & & 1 & \\
\hline 6 & & 5 & & 14 & & 3 & \\
\hline 12 & & 7 & & 20 & & 9 & \\
\hline 15 & & 8 & & 22 & & 16 & \\
\hline 17 & & 10 & & 25 & & 18 & \\
\hline 19 & & 11 & & 28 & & 23 & \\
\hline 21 & & 26 & & 29 & & 27 & \\
\hline 24 & & 30 & & 32 & & 33 & \\
\hline 34 & & 31 & & 35 & & & \\
\hline Total & & & & & & & \\
\hline
\end{tabular}

Conclusão:

Psicólogo Responsável: 
This document was created with Win2PDF available at http://www.win2pdf.com.

The unregistered version of Win2PDF is for evaluation or non-commercial use only. This page will not be added after purchasing Win2PDF. 